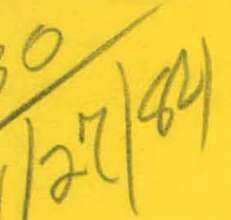

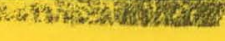
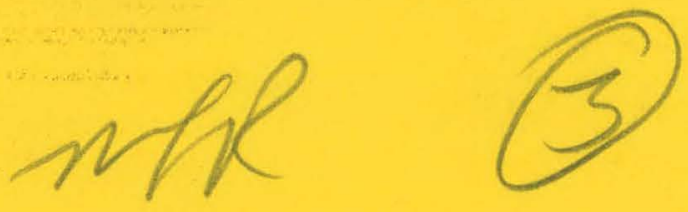

$D R+0635-1$

\title{
SOLAR/0013-84/30
}

(DE85001385)

\section{A SURVEY OF REMOTE DATA MONITORING SYSTEMS}

September 1984
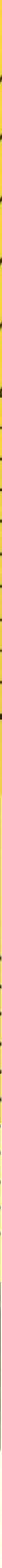

U.S. DEPARTMENT OF ENERGY NATIONAL SOLAR DATA PROCRAM 


\section{DISCLAIMER}

This report was prepared as an account of work sponsored by an agency of the United States Government. Neither the United States Government nor any agency Thereof, nor any of their employees, makes any warranty, express or implied, or assumes any legal liability or responsibility for the accuracy, completeness, or usefulness of any information, apparatus, product, or process disclosed, or represents that its use would not infringe privately owned rights. Reference herein to any specific commercial product, process, or service by trade name, trademark, manufacturer, or otherwise does not necessarily constitute or imply its endorsement, recommendation, or favoring by the United States Government or any agency thereof. The views and opinions of authors expressed herein do not necessarily state or reflect those of the United States Government or any agency thereof. 


\section{DISCLAIMER}

Portions of this document may be illegible in electronic image products. Images are produced from the best available original document. 


\section{DISCLAIMER}

This report was prepared as an account of work sponsored by an agency of the United States Government. Neither the United States Government nor any agency thereof, nor any of their employees, makes any warranty, express or implied, or assumes any legal liability or responsibility for the accuracy, completeness, nr usefulness of any information, apparatus, product, or process disclosed, or represents that its use would not infringe privately owned rights. Reference herein to any specific commercial product, process, or service by trade name, trademark, manufacturer, or otherwise does not necessarily constitute or imply its endorsement, recommendation, or favoring by the United States Government or any agency thereof. The views and opinions of authors expressed herein do not necessarily state or reflect those of the United States Government or any agency thereof.

This report has been reproduced directly from the best available copy.

Available from the National Technical Information Service, U. S. Department of Commerce, Springfield, Virginia 22161.

Price: Printed Copy A04

Microfiche A01

Codes are used for pricing all publications. The code is determined by the number of pages in the publication. Information pertaining to the pricing codes can be found in the current issues of the following publications, which are generally available in most libraries: Energy Research Abstracts (ERA); Government Reports Announcements and Index (GRA and I); Scientific and Technical Abstract Reports (STAR); and publication NTIS-PR-360 available from NTIS at the above address. 


\title{
A SURVEY OF REMOTE DATA MONITORING SYSTEMS
}

Prepared by:

T.L. Logee

P.W. Kendall

E. O. Pollock

M.G. Raymond

R.C. Knapp, Jr.

Approved by:

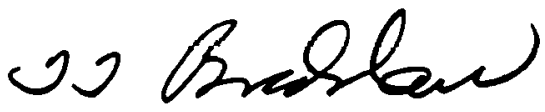

T.T. Bradshaw

Program Manager

\author{
Vitro Corporation \\ 14000 Georgia Avenue \\ Silver Spring, Maryland 20910
}

The National Solar Data Network

Department uf Energy Contract Number DE-ACOI-79CS30027 


\section{FOREWORD}

The National Solar Data Network (NSDN) was established in 1974 as part of the National Solar Demonstration Program. Datalogger development by the IBM Corporation preceded the actual solar system monitoring. Monitoring began in 1977. Since 1977, over 170 solar systems have been instrumented and monitored for periods as long as three years.

This report was commissioned by the Department of Energy (DOE) to relate the NSDN experience with the original remote data monitoring system. The objective of the study is to identify suitable replacements for the Site Data Acquisition equipment. It is expected that the newer dataloggers would have more capabilities, better accuracy, and higher reliability than the present equipment. 
THIS PAGE

WAS INTENTIONALLY

LEFT BLANK 


\section{TABLE OF CONTENTS}

Section

Page

F OREWORD

TABLE OF CONTENTS

LIST OF ILLUSTRATIONS

LIST OF TABLES

INTRODUCTI ON

I INSTRUMENTATION

II PRESENT AND FUTURE DATALOGGER REQUIREMENTS

11.1 Present NSDN SDAS Capabilities

II.2 Improvements to the NSDN System

27

11.3 Dataloggers by Manufacturers

III COMMUNICATIONS WITH A REMOTE DATALOGGER

37

IV CENTRAL FACILITY DATA PROCESSING

$\checkmark \quad$ CONCLUSIONS AND RECOMMENDATIONS $\quad 49$

VI REFERENCES

Appendix
A Datalogger Manufacturers
$A-1$
B Datalogger Specifications
$B-1$ 


\section{LIST OF ILLUSTRATIONS}

Figure

Number

1 Typical Temperature Sensor/Thermowell Mounting Locations for Liquid Systems

2 SDAS Functional Block Diagram

3 The SDAS/J-BOX Configuration

4 Representation of Datalogger System

5 Sequence of Data Collection Operations

6 Site collection Sequence

7 The National Solar Data Network
Page

40

45 
LIST OF TABLES

\begin{tabular}{cl}
$\begin{array}{c}\text { Table } \\
\text { Number }\end{array}$ & \multicolumn{1}{c}{ Title } \\
\hline 1 & Approved Master Sensor List \\
2 & Temperature Probe Characteristics \\
3 & Evaluation of Temperature Sensors \\
4 & Recommended Transducers \\
B-1 & Cataloger Specifications
\end{tabular}

Page

4

11

12

18

$B-1$

v 
The National Solar Data Network (NSDN) was originally established as part of the National Solar Demonstration Program. The intent of the NSDN was to provide measured data on the field performance of solar energy systems. The NSDN was designed to use telecommunications of the field-measured data to a central processing facility. However, at the time the NSDN was established, a practical low-cost telecommunications datalogger did not exist.

The Department of Energy (DOE) commissioned the IBM Corporation to build a device which could collect data and transmit the collected data back to a central facility. IBM built a self-contained datalogger device called an SDAS (Site Data Acquisition Subsystem) which could collect analog data from 96 channels, store the data for up to three days, and then transmit the stored data on request to a central facility by voice-grade telephone lines. This system has worked fairly well for the eight years that it has been in service. However, the design and components are getting old and newer dataloggers may be more reliable and accurate and less expensive.

This report discusses the results of an extensive search for an SDAS replacement. The survey covered 62 models from 36 manufacturers. These numbers are not indicative of all the dataloggers or manufacturers available, but only those which appeared to have some qualifications for the NSDN datalogger replacement.

This report views the datalogger as a system which is made up of sensors, a data acquisition and storage unit, a telecommunications subsystem, and a data processing subsystem. Therefore, there is a section on sensors used in the NSDN, telecommunications technology, and data processing requirements. These four components or subsystems are all necessary in order to have an integrated, successful remote data monitoring network. 
THIS PAGE

\section{WAS INTENTIONALLY LEFT BLANK}




\section{SECTION I}

\section{INSTRUMENTAT I ON}

This section will discuss the following primary measurements:

- Temperature

- Flow (Liquid)

$(A i r)$

- Electric Power

- Insolation (Solar Radiation)

- Fuel gas flow and fuel oil flow

- Relative Humidity

followed by a discussion of recommendations for future sensor types.

To date, the NSDN system (developed by IBM Corporation and continued by Vitro Corporation) has utilized a large number of transducers to monitor over 170 solar systems. These sensors are listed in Table 1, the NSDN Approved Master Sensor List.

One of Vitro Corporation's NSDN program efforts was the control, improvement, and consolidation of sensor utilization for the NSDN program. The first step in controlling sensor utilization was the preparation of a master list of approved sensors for NSDN applications, as in Table 1 .

The sensors were approved after a process involving the Marshall Space Flight Center, the National Bureau of Standards, the Argonne National Laboratory ( $A N L$ ), and the Department of Energy (DOE). Approval of commerclaliy available sensors was granted based on supplier-provided accuracy and reliability information. New sensors were chosen, documented and tested in the field and the results were reviewed by ANL and DOE.

This Approved Master Sensor List was used in the NSDN program by vitro corporation as the baseline list of approved sensors. 
Table 1. APPROVED MASTER SENSOR LIST

\begin{tabular}{|c|c|c|c|}
\hline DATA REQUIREMENT & NAME & MANUFACTIJRER & MODEL \\
\hline $\begin{array}{l}\text { Ambient Outside Air } \\
\text { Temperature }\end{array}$ & $\begin{array}{l}\text { Resistance Temper- } \\
\text { ature Detector }\end{array}$ & Minco & S53P, S57P \\
\hline $\begin{array}{l}\text { Ambient Sensor } \\
\text { Enclosure }\end{array}$ & (Radiation Shield) & (WeatherMeasure) & $154, \quad 152$ \\
\hline Angular Displacement & $\begin{array}{l}\text { Precision Fotentio- } \\
\text { neter }\end{array}$ & $\begin{array}{l}\text { New England Instru- } \\
\text { ments }\end{array}$ & $78 E B 0502$ \\
\hline \multicolumn{4}{|l|}{ Differential } \\
\hline$($ L iquid) & Pressure & Robinson-Halpern & $1500 / 1550$ \\
\hline Diffuse Radiation & $\begin{array}{l}\text { Pyranometer } \\
\text { N/Shadowbend }\end{array}$ & Eppley & PSP w/Shadowband \\
\hline \multirow[t]{4}{*}{ Discrete Switch } & Contact Switch & Radio Shack/Archer & $P / N \quad 275-495$ \\
\hline & $\begin{array}{l}\text { Electrical Relay } \\
\text { Switch }\end{array}$ & Magnecraft & $P / N \quad W 88 A C P X-3,4$ \\
\hline & Temperature Switch & Fenwall & $30002-0$ \\
\hline & Microswitch & Denison & $\mathrm{C} 2 \mathrm{~T}-\mathrm{J}$ \\
\hline Electrical Power & Watt Transducer & Ohio Semitronics & $P C 5-Y Y F$ \\
\hline \multirow[t]{2}{*}{ Flow Rate (Air) } & Flow Meter & $\begin{array}{l}\text { Dietrich jtd. } 1 \\
\text { Robinson-talpern }\end{array}$ & $\begin{array}{l}\text { Type } 74 \\
157 \mathrm{~A}\end{array}$ \\
\hline & Air Velocity Meter & $\begin{array}{l}\text { Kurz Instrument } \\
\text { Anemometer }\end{array}$ & $\begin{array}{l}430-x-x x \\
430-0 C\end{array}$ \\
\hline
\end{tabular}


Table I. APPRQVED MASTER SENSOR LIST (Continued)

DATA REQUIREMENT

Flow Rate (Liquid)

Fuel oil

Gas

Heat Flux

Inside Ambient

Position Indicator

Relative Humidity

Surface Temperature

Temperature (Air)
NAME

Flow Meter

Flow Meter

Totalizer

Flow Meter

Fuel 0 il Meter

Gas Meter

Heat Flow Meter

Resistance Temperature Detectors

Linear Position

F:H Probe

Fiesistance Temperature Detectors

Resistance Temperature Detectors
MANUFACTURER

MODEL

Ramapo

Floscan

Hersey-Niagara

Hersey-American

American Meter

Hersey

Kent

American Meter

$H Y-C A L$

Minco

Potentiometer Research, Inc.

WeatherMeasure

Minco

Minco

$M K-V$

$300-3$

$10,20,21,22$, etc.

$430,530,540$, etc.

$432,532,542$, etc.

$10,20,21$, etc.

4 Mini Major/ Metron

Diaphram Meter

BIX $-7 X$

S 7850

$R 14040-10$

$H M 111-P, H M 14-U$

$S 34 A, S 32 B, S 7301$

S53P, S57P, S7850 
Table 1. APPRCLED HASTER SENSOR LIST (COntinued)

\begin{tabular}{|c|c|c|c|}
\hline DATA REQUIREMENT & NAME & MANUFACTURER & MODEL \\
\hline Temperature (Liquid) & $\begin{array}{l}\text { Si igle Element } \\
\text { Rəsistance Tempera- } \\
\text { t dre Detectors }\end{array}$ & Minco & S53P, S54P \\
\hline & $\begin{array}{l}\text { Dual Element } \\
\text { Resistance Tempera- } \\
\text { ture Detectors }\end{array}$ & Minco & S57P, S59P \\
\hline Total Radiation & Pyranometer & Eppley & PSP \\
\hline $\begin{array}{l}\text { Wind Velocity and } \\
\text { Direction }\end{array}$ & S<yvane 1 & WeatherMeasure & $\begin{array}{l}W 101-P-D C / 540 \\
W 102-P-D C / 360\end{array}$ \\
\hline
\end{tabular}


At present, the NSDN utilizes Minco Products S53P platinum Resistance Temperature Detectors (RTD). Because the resistance of platinum wire varies as a function of temperature, measurements of the resistance of a calibrated length of platinum wire can be used to accurately determine the temperature of the wire. This concept is the principle of the platinum RTD which utilizes a tiny coil of platinum wire encased in a copper-tipped probe to measure temperature.

Ambient temperature sensors are housed in a WeatherMeasure Radiation Shield in order to protect the probe from solar radiation. Care is taken to locate the sensor away from extraneous heat sources which could produce erroneous temperature readings. Temperature probes mounted in pipes are installed in stainless steel thermowells for physical protection of the sensor and to allow easy removal and replacement of the sensors. A thermallyconductive grease is used between the probe and the thermowell to assure faster temperature response.

All temperature sensors are individually. calibrated at the factory. In addition, the bridge circuit is calibrated in the field using a five-point check.

Nominal Resistance@ $25^{\circ} \mathrm{C}$ :

No. of Leads:

Electrical Connection:

Time Constant:

Self-Heating:
100 ohms

3

Wheatstone Bridge

1.5 seconds max. in water

at $3 \mathrm{fps}$

$27 \mathrm{mw} / \mathrm{OF}^{\mathrm{F}}$

These RTD probes have proven to be reliable, yet some problems in using them have been found. These are briefly outlined below.

a. Individual calibration of Wheatstone bridges in the SDAS is performed using a "five-point" resistance check whereby five known input resistance values are input to the bridge circuit (replaclng the RTD) and five readings of SDAS channel output (in digital counts ranging from 0 to 1023) are recorded. These five-point check values, along with the measured value of excitation voltage (the nominal + $15 \mathrm{~V}$ applied to the sensor for the purpose of measuring. the probe's resistance), wire loop resistance (in ohms), and individual sensor calibration data are input to the NSDN CDPS (Central Data Processing System) for calculation of sensor-specific counts to engineering unit curve fitting equations. These equations are the final step in converting count values to engineering values.

If the bridge circuit changes resistance characteristics during operation (due to physical or thermal stress, for example), then the temperature readings will be affected. In addition, changes in wire resistance will affect the 
sensor final readings as well. Both of these problems, bridge instability and wiring connection resistance changes, have been found to affect the NSDN data. The entire five-point check process is time-consuming as well, and adds to the cost of the overall system.

b. Thermal mass (and therefore the time constant) of the RTD sensor/stainless steel thermowell is quite high. In some cases, the thermal response time of the sensor/ thermowell combination can cause a bias which will affect the energy balance calculations. Fluids which undergo transitions in temperature at a rate which is faster than the response time will require sensors with a smaller time constant ( $i . e$. , faster thermal response time). The dynamic response of a temperature probe is a function of its mass and thermal heat storage capacity, as woll as its heat transfor ohoracterigtics (ieluted lu lis slze, length, and length to diameter latiu).

There are cases whore a long thcrmal log will cause all effective negative bias on sensor readings.

c. The RTD/thermowell combination used in liquid systems and a bare RTD mounted in a duct, for example, can both exhibit significant stem conduction errors due to the physical configuration of the sensor installation. Steps are taken to insulate all probes, and minimize excessive unwetted probe length, but often the system being monitored will not have appropriate mounting locations for the probes.

In the case of liquid systems, Figure l indicates two methods of installing RTD/thermowell combinations, Method $C$ (a run tee) and 0 (an elbow tee) configurations. Method $D$ is preferable, since it places more of the RTD/ thermowell stem in the actual flow, while Method $c$ leaves the probe stem in a less turbulent pool of fluid in the arm of the tee.

A theoretical analysls of the sensor/thermoweli combination indicates that reduction of stem conduction errors may be accomplished by:

1) Keepling the probe stem thermal conductivity as low as pussible.

2) Increasing the immersion length and reducing the diameter of the probe.

3) lincieasing the surface heat transfer rate. 

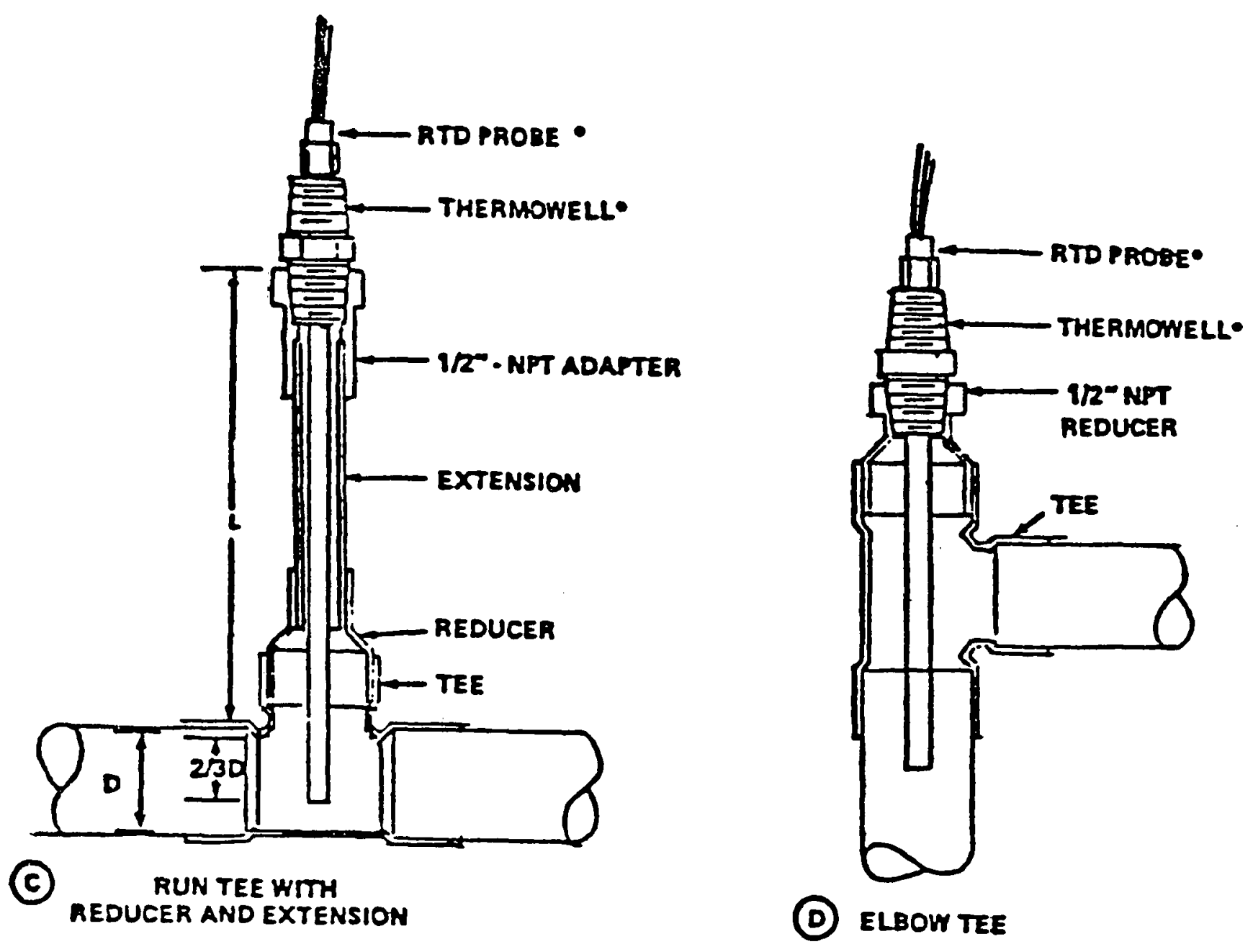

Figure 1. Typical Temperature Sensor/Thermowell Mounting Locations for Liquid Systems 
d. Other placement errors can occur, such as placement of RTD probes in poor locations in the system (i.e., in pipes which are not full of fluid, in ducts with internal thermal gradients), probes which are not seated in the thermowells, excessive applications of thermally conductive grease which increase stem conduction errors, radiation effects, and poorly insulated probes. These placement errors can generally be minimized by careful checkout of the system.

There are other types of temperature probes in use which may be applicable to NSDN-type monitoring schemes used with the dataloggers described in section $V$. Table 2 shows some of these probes and their characteristics.

In all cases, the resolution of critical small temperature diffcrences represents a significant barrier to resolution of energy flows in solar and energy systems. The thcrmopilc system (where a series of thermocouple junctions are used to resolve small temperature differences) may provide some added accuracy when using the newer dataloggers. Differential bridge circuits using matched RTDs are another possibility.

Table 3 presents a subjective or relative evaluation of four types of temperature sensors, $100 \Omega$ platinum RTD, thermistor, thermocouple, and solid-state semiconductor devices.

Each evaluation category (cost, temperature range, etc.) has a rating (good, high, low, etc.) for the four types of probes discussed.

There are obvious tradeoffs to be considered when a probe type is selected for deployment at a large number of sites, including cost, stability, long-term performance, interchangeability, etc. No one type of probe will ideally meet all criteria.

Elimination of the thermowell may be desirable in future monitoring. A P/T (Pete's Plug) fitting may be used to provide a port for direct measurement of fluid temperature by an appropriate probe (RTD, thermistor, thermocouple, or solid-state). Thinner probes may also reduce stem conduction and time constant errors.

Flow (Liquid) Sensors

The flow of fluids in solar systems (either liquid or air) reprerontr n relatively difficult parameter to muasiou. Al prusenl, liquid flow is sensed using:

- Totalizing flow meters (nutating disc type)

- Target-type impact meters

Air flow is measured using:

- Thermal anemometers 
Table 2. TEMPERATURE PROBE CHARACTERISTICS

\section{TYPE OF SENSOR \\ integrated Circuit}

Transoucer

RTDS

ilicon Planar

Temperature Sensors

Thermistors

Thermocouples
TYPICAL RANGE

$-55^{\circ} \mathrm{C} / 150^{\circ} \mathrm{C}$

$-200^{\circ} \mathrm{C} / 900^{\circ} \mathrm{C}$

$-65^{\circ} \mathrm{C} / 300^{\circ} \mathrm{C}$

$78 \Omega /{ }^{\circ} \mathrm{C}$ Typical $7.581^{\circ} \mathrm{C}$

2,0005 Typical

SENSOR OUTPUT/

$\mathrm{I} \mu \mathrm{A} /{ }^{\circ} \mathrm{C}$

$10-20,000 \Omega$

$0.22 \Omega /{ }^{\circ} \mathrm{F}$

$0-50 \mathrm{mv}$

$0-50 \mathrm{mv}$

$0-50 \mathrm{mv}$

\section{COMMENTS}

Current-based integrated circuit temperature sensors. Two terminal. Highly linear. Packaging poor. Low noise susceptibility.

Requires bridge circuit. Stable. Lead wires resistance affect readings. Used widely for precision weating tivity, small changes in resistance per tegree of temperature.

Relies on change in resistance with temperature exhibited by silicon. Requires complex bridge circuit to resolve temperature. Out put nonlinear. Fast response time. Small size.

May exhibit drift in use. Narrow temperature ranges. Similar circuitry as for RTDS required. Solid-state devices. Requires no special leas physically and chemically stable. Available in a variety of configurations Aubject to self-hearing. High rations. Avabject to selfareacing. High

Thermocouples require reference junctions, sensitive measurement of mv. Inexpensive probes. Wiring costs high. Special connectors required. May have grounding prob lems. Wire length affects readings over 200 feet. May be wired in series/parallel to resolve small temperature differences. May require special shielding. Used in laboratory and testing. 
Table 3. EVALUATION OF TEMPERATURE SENSORS

\begin{tabular}{|c|c|c|c|c|}
\hline $\begin{array}{l}\text { EVALUATI ON } \\
\text { CRITERIA } \\
\end{array}$ & $\begin{array}{l}\text { PLATINUM RTD } \\
\text { IOO } \Omega \text { WIRE } \\
\text { WOUND AND } \\
\text { THIN FILM } \\
\end{array}$ & THERM I STOR & THERMOCOUPLE & $\begin{array}{c}\text { SEMI- } \\
\text { CONDUCTOR } \\
\text { DEVICES } \\
\end{array}$ \\
\hline $\cos t$ & $\mathrm{High}$ & Low & Low & Low \\
\hline Temperature Range & $\begin{array}{l}\text { Wide } \\
-400^{\circ} \mathrm{F} \text { to } \\
+1200^{\circ} \mathrm{F} \\
\star\end{array}$ & $\begin{array}{l}\text { Short to } \\
\text { Medium } \\
-100^{\circ} \mathrm{F} \text { to } \\
+500^{\circ} \mathrm{F}\end{array}$ & $\begin{array}{l}\text { Very Wide } \\
-450^{\circ} \mathrm{F} \text { to } \\
+4200^{\circ} \mathrm{F} \\
+\star\end{array}$ & $\begin{array}{l}\text { Short } \\
-57^{\circ} \mathrm{F} \text { to } \\
+257^{\circ} \mathrm{F}\end{array}$ \\
\hline Interchangeability & $\begin{array}{l}\text { Excel lent } \\
\star \star\end{array}$ & $\begin{array}{l}\text { Poor to } \\
\text { Fair }\end{array}$ & $\begin{array}{l}\text { Good } \\
\star\end{array}$ & Fair \\
\hline Long-Term Stability & Good & Pour $r^{2}$ & $\begin{array}{l}\text { Foor to } \\
\text { Fair }\end{array}$ & $\begin{array}{l}\text { Good lo } \\
\text { Fair }\end{array}$ \\
\hline Accuracy & $\begin{array}{l}H \operatorname{lgh} \\
\star\end{array}$ & Medium & Medium & Medium \\
\hline Repeatability & $\begin{array}{l}\text { Excellent } \\
\star \star\end{array}$ & $\begin{array}{l}\text { Fair to } \\
\text { Good }\end{array}$ & $\begin{array}{l}\text { Poor to } \\
\text { Fair }\end{array}$ & $\begin{array}{l}\text { Good } \\
\star\end{array}$ \\
\hline Sensitivity (output) & Medlum & $\begin{array}{l}\text { Very HIgh } \\
\star \star\end{array}$ & Low & $\stackrel{\operatorname{High}}{\star}$ \\
\hline Response & Medium & $\begin{array}{l}\text { Medium to } \\
\text { Fast } \\
\star\end{array}$ & $\begin{array}{l}\text { Medium to } \\
\text { Fast } \\
\star\end{array}$ & $\begin{array}{l}\text { Medium to } \\
\text { Fast } \\
\star\end{array}$ \\
\hline Linearity & Good & Puor & Fair & Good \\
\hline Self-Heating & $\begin{array}{l}\text { Very Low } \\
\text { to Low } \\
\Rightarrow\end{array}$ & $\mathrm{High}$ & N/A & $\begin{array}{l}\text { Very Low } \\
\text { to Low } \\
\text { t }\end{array}$ \\
\hline Point (end) Sensitive & Fair & Good & $\underset{\star}{\text { Excel lent }}$ & Good \\
\hline Lead Effect & Medium & $\begin{array}{l}\text { Very Low } \\
\star \star\end{array}$ & $\mathrm{High}$ & $\stackrel{\text { Low }}{\star}$ \\
\hline Physical size/Packaging & $\begin{array}{l}\text { Mediuiii Lu } \\
\text { Small }\end{array}$ & $\begin{array}{l}\text { Sulli In } \\
\text { Medium } \\
\star\end{array}$ & $\begin{array}{l}\text { SIIA1! in } \\
\text { Large } \\
\star\end{array}$ & $\begin{array}{l}\text { smạ! ! to } \\
\text { Mediull } \\
\star\end{array}$ \\
\hline
\end{tabular}




\section{Liquid Flow Sensors (Totalizing)}

Hersey Series 400 flow meters are used to measure totalized liquid flow. The sensor is a nutating disk, positive displacement type meter. An R-15 register with an SPDT reed switch is used to provide an output to the data acquisition subsystem.

The output of the reed switch is input to a Martin DR-1 Digital Ramp which counts the number of pulses and produces a zero to five volt analog signal corresponding to the pulse count.

Materials:

Meter body - bronze

Accuracy: Measuring chamber - plastic $\pm 1.5 \%$

Newer dataloggers with pulse counting and scaling capabilities are ideal for use with the R-15 registers.

Few problems have been encountered with these flow meters, although some of the minor problems encountered are:

- There are occasions when an extremely low flow of fluid will pass through larger flow meters without registering. Some high flows will spin the nutating disc very rapidly, causing premature wear and excessive noise (acoustic). The sensor may be mismatched to the flow.

- Some flow meters have been mounted improperly, i.e., not in a horizontal line, causing problems.

- The discs used in these meters have temperature-range specific requirements. High temperatures can cause measurement problems and/or sensor failure due to disc damage. That is, there is a possible mismatch of disc material to flow temperature.

- Since these meters depend on relatively close tolerances, they are sensitive to dirty or particulate-laden fluids.

2. Liquid Flow Sensors (Non-Totalizing)

The Ramapo Mark V strain-gauge flow meters are used for the measurement of liquid flow. The flow meters sense the flow of the liquids by measuring the force exerted by the flow on a target suspended in the flow stream. This force is transmitted to a four active arm strain-gauge bridge to provide a signal proportional to flow rate squared. The flow meters are available in a screwed end configuration, a flanged configuration, and a wafer configuration. Each flow meter is calibrated for the particular fluid being used in the application. 
Materials:

Fluid Temperature:

Calibration Accuracy:

Repeatability and

Hysteresis:
Target - 17-pH stainless steel Body - Brass or stainless steel Seals- Buna-N $-40^{\circ} \mathrm{F}$ to $250^{\circ} \mathrm{F}$

$\pm 1 \%\left(\frac{1}{2} " 1\right.$ to $3 \frac{1}{2} " 1$ line size)

$\pm 2 \%$ (4" and greater line size)

$0.25 \%$ of reading

The strain-gauge type meters have had a number of significant probems in the field environment.

- During low flow rates (variable flow - under conditions where the flow rate varies), the Ramapo meters are a poor choice. The meters should have flow not less than 75\% of rated capacity. Thus, variable flow loops are not accurately monitored by these meters.

- Mounting, as with the positive displacement meters, of chese straln-gauge type meters requires a horizontal mount. In addition, they require a significant length of. straight piping before and after the meter, usually 20 diameters before and 10 diameters after the probe.

- Permanent deflection or excessive noise, if a small particle lodges between the disc and the body of the meter, may become quite large. In addition, these meters may permanently deflect under extreme conditions, causing excessive noise levels.

- Since the flow meter depends on creating a pressure drop (and thus a force on the target which deflects the bar to which. the strain gauges are attached) by forcing the flow through an annular space, chere are systems which will be negatively impacted by the use of these meters with a high pressure drop.

Based on Vitro Corporation's experience, it is recommended that both the positive displacement (nutating disc) and impact-type flow meters be retained. There does not seem to be any type meter having a better cost/performance tradeoff.

Flow (Air) Sensors

The Kurz 430 Series of thermal anemometers is used for the measurement of air flow. The basic sensing element is a probe which consists of a velocity sensor and a temperature sensor. The velocity sensor is heated and operated as a constant temperature thermal anemometer which responds to a "standard" velocity (referenced to $25^{\circ} \mathrm{C}$ and $760 \mathrm{~mm} \mathrm{Hg}$ ) or mass flow by sensing the cooling effect of the air as it passes over the heated sensor. 
The temperature sensor compensates for variations in ambient temperature.

Since the probe measures air velocity at only one point in the cross section of the duct, it is necessary to perform a careful duct mapping to relate the probe reading to the amount of air flowing through the entire duct. This is done by dividing the duct into small areas and taking a reading at the center of each area using a portable probe. The readings are then averaged to determine the overall duct velocity. The reading at the permanently installed probe is then ratioed to this reading. This duct mapping is done for each mode.

Accuracy:

Response Time:

Repeatability:

$$
\begin{aligned}
& \pm 2 \% \text { of full scale over tem- } \\
& \text { perature range }-20^{\circ} \mathrm{C} \text { to } 60^{\circ} \mathrm{C} \\
& \pm 5 \% \text { of full scale over tem- } \\
& \text { perature range }-60^{\circ} \mathrm{C} \text { to } 250^{\circ} \mathrm{C} \\
& 0.025 \text { second } \\
& 0.25 \% \text { full scale }
\end{aligned}
$$

While the measurement of duct air flow is difficult, there does not appear to be any substitute for the thermal anemometer.

\section{Electric Power Sensors}

Ohio Semitronics Series PC5 wattmeters are used as electric power sensors. They utilize Hall-effect devices as multipliers taking the product of the instantaneous voltage and current readings to determine the electrical power. This technique automatically takes power factor into consideration and produces a true power reading.

A major component of the wattmeter is a concentrating magnetic core (usually a toroid). The conductor carrying current to the load is passed through the window (eye) of the magnetic core one or more times. The magnetic field surrounding the conductor (loadcarrying wire) is instantaneously proportional to the current flowing in the conductor. This field is intercepted by the magnetic core, producing a magnetic flux which is also instantaneous ly proportional to the current flowing in the conductor. A Hall-effect transducer is cemented into a thin slot milled through the concentrating magnetic core.

In this position it intercepts nearly all of the magnetic flux present in the core. Two of the transducer's terminals provide a full scale output of $50 \mathrm{mV} D C$. The remaining two terminals are referred to as a control input. The output of the Hall transducer is not only proportional to the magnetic flux passing through it but also to any EMF which appears across its control terminals. The load voltage is applied to the transducer's control terminals. 
The resultant measurements of the wattmeter are summarized below:

- Output is directly proportional to the flux in the magnetic core which in turn is directly proportional to the load current ( 1 ).

- Output is directly proportional to the load voltage (E).

- Final output is directly proportional to the vector product of $E, 1$, and $\cos \phi$ (power factor angle). This output is read into the SDAS as an electrical power in watts.

$\begin{array}{ll}\text { Power Factor Range: } & 1 \text { to } 0 \text { (lead or lag) } \\ \text { Response Time: } & 250 \mathrm{~ms} \\ \text { Temperature Effect: } & 1 \% \text { of reading } \\ \text { Accuracy: } & 0.5 \% \text { of full scale }\end{array}$

These meters are stable, accurate, and well-suited to this. type of field monitoring procedures. The only problems with these meters relate to ranging (they must be selected for proper voltage, power, and wiring configuration) and actual wiring errors (toroids wired improperly, signal wires backwards, etc.).

Standard ki lowatt-hour meters as used by utility companies having pulsed output or dry contacts can be monitored using a data logger having pulse counting capability. This scheme has no advantage, however, over the Hall-effect watt transducers.

Another method for estimating power consumption by electrical components is the elapsed-time sensor, which is a relay (wired to close on activation of the component) which feeds a ramp-type electronic device known as a Martin Electronics Elapsed Time Ramp. The device provides a ramping voltage to the SDAS in proportion to the amount of time the device is active. The output readings resemble a liquid totalizer output, except the values are in minutes, rolling over at 30-minute totals.

Insolation Sensors

The Eppley Model PSP pyranometer is used for the measurement of insolation. The pyranometer consists of a circular multijunction thermopile of the plated (copper-constantan) wirewound type which is temperature compensated to render the response essentially independent of ambient temperature. The receiver is coated with Parsons' black lacquer (non-wavelength-selective absorption). The instrument is supplied with a pair of precision-ground polished concentric hemispheres of schot optical glass transparent to light between 285 and $2800 \mathrm{~nm}$ of wavelength. The instrument is provided with a dessicator which may be readily inspected. Pyranometers designated as shadowband pyranometers are equipped with a shadowband which may be adjusted to block out any direct solar radiation. These instruments are used for the measurement of diffuse insolation. 
Sensitivity:

Temperature Dependence:

Linearity:

Response Time:

Cosine Error:
$9 \mu \mathrm{V} / \mathrm{W} / \mathrm{m}$

$\pm 1 \%$ over ambient temperature range $-200 \mathrm{C}$ to $400 \mathrm{C}$

$0.5 \%$ from I to $2,800 \mathrm{~W} / \mathrm{M}$

1 second

$\pm 1 \% 0$ to $70^{\circ}$ zenith angle

$\pm 3 \% 70$ to 800 zenith angle

There are considerably less expensive devices of the solid-state type which will provide similar levels of accuracy. These solidstate devices use a photocell as the transducer, rather than a thermometric-type of conversion from incident radiation to a measurable signal. The response time of the solid-state devices is smaller than with the thermal device, but cosine error (error due to the beam angle being less than 90 degrees from the plane of the detector) can be greater, particularly at lower sun angles.

Fuel Gas and Fuel oil Flow Sensors

The American AC-175 gas meter is used for the measurement of totalized fuel gas flow. The drop in pressure between the inlet and outlet of the meter is responsible for the action of the meter. The principle of measurement is positive displacement. Four chambers in the meter fill and empty in sequence. The exact volume of compartments is known, so, by counting the number of displacements, the volume is measured. Sliding control valves control the entrance and exit of the gas to the compartments. The meter is temperaturecompensated to reference all volumetric readings to $600 \mathrm{~F}$.

Rated Capacity:

Max Working Pressure:
$175 \mathrm{ft} 3 / \mathrm{hr}$

5 ps i

Vitro Corporation has modified existing gas meters (where applicable) with a potentiometer located on the readout dial, so that the position of the dial is proportional to the output voltage from the potentiometer.

The Kent Mini-Major is used as a fuel oil flow meter. The meter utilizes an oscillating piston as a positive displacement element. The oscillating piston is connected to a pulser which sends pulses to the SDAS tor totalization.

$\begin{array}{ll}\text { Operating Temperature: } & 100^{\circ} \mathrm{C}(\max ) \\ \text { Flow Range: } & 0.6 \text { to } 48 \text { gph } \\ \text { Accuracy: } & \pm 1 \% \text { of full scale }\end{array}$

The measurement of fuel oil flow is often complicated by a return oil flow line, requiring two meters and a subtraction calculation to yield actual fuel consumption. 


\section{Relative Humidity Sensors}

The WeatherMeasure HMP-14U Solid State Relative Humidity Probe is used for the measurement of relative humidity. The operation of the sensor is based upon the capacitance of the polymer thin film capacitor. A one-micron-thick dielectric polymer layer absorbs water molecules through a thin metal electrode and causes capacitance change proportional to Relative Humidity (RH).

$\begin{array}{ll}\text { Range: } & 0 \text { to } 100 \% \text { RH } \\ \text { Response Time: } & \text { I second to } 90 \% \text { humidity } \\ & \text { change at } 200^{\circ} \\ \text { Temperature Coefficient } & 0.05 \% \text { RH } /{ }^{\circ} \mathrm{C} \\ \text { Accuracy: } & \pm 3 \% \text { from } 0 \text { to } 80 \% \text { RH } \\ \text { Sensitivity: } & \pm 5 \text { to } 6 \% \text { to } 80 \text { to } 100 \% \text { RH } \\ & 0.2 \% \text { RH }\end{array}$

Unfortunately, these $\$ 750$ probes have had a poor operational history in the NSDN. Alternative, low-cost probes [\$7.50 each-such as the MEPcu/tlectra (a division of Nurlh Alltician fhillips Co.) Relative Humidity Sensor $5 \times 38 H 122 R$ ] will be more cost-effective, and certainly as reliable.

\section{RECOMMENDATIONS}

Based on the experience gained on the NSDN, Table 4 summarizes Vitro Corporation's recommendations for future NSDN-type long-term monitoring of systems. Table 4 is a compilation of first and second choice transducers for temperature, thermowells, flow (liquid), flow (air), insolation, electric power, and humidity.

\section{Table 4. RECOMMENDED TRANSDUCERS}

$$
\text { Temperature }
$$

Thermowells

Flow (Liquid)

Flow (Air)

Insolation

Electric Power

Humidity

\section{RTD}

Solid Statc

None, Use Pete's PIug

Nutating Disc

Thermal Anemometer

Solid-State Photocell

Watt Transducer

Low Cost Capacitance Type
Thermocouples

Therinistur

Stainless Steel

The rmowe 11

Turbine Meters

None

Thermal Pyranometer

Pulse-output Wat tmeter

None 
Either RTDs or solid-state temperature probes should be considered. RTDS provide a standard, interchangeable sensor, but reading them presents some problems due to relatively low sensitivity (unit change in output for unit change in temperature). There are some modern RTDs which do not use the platinum coil construction technique, known as thin-film RTDs, which may be an improvement over the 100 ohm RTDs in use at present.

The solid-state devices appear to be accurate, reliable, and simple to use, with the major problem being packaging. Most sold-state devices are not durably packaged in a steel case, but newer models are constantly being developed. Low-cost solid-state sensors combined with low-cost digital dataloggers appear to be a significant advance in the area of temperature sensing.

Thermocouples are not a first choice, due to the following reasons:

- Each thermocouple requires special extension wire, likemetal connectors, etc., which increases wiring costs.

- The dataloggers require a reference junction.

- Accuracy may be lower than RTDs or solid-state.

Thermistors present calibration drift problems. Thermistors are inexpensive, however, and relatively inexpensive units can be used to read them.

Thermowells may be eliminated by using $P / T$ plugs to directly immerse the temperature probes in the liquid flow. Air measurements do not present this problem.

Nutating disc flow meters using a pulse register have been the most accurate and reliable flow sensors used in the NSDN.

While the spectral response and cosine response of photocell-type pyranometers are less accurate than the precision spectral pyranometers, the cost reduction through their use makes them a justifiable choice.

The present Hall-effect type watt transducers perform very well. Elapsed-time meters for components having relatively constant power draw are sufficient for calculation of parasitic power use.

Low-cost capacitance-type relative humidity sensors to replace the high-cost capacitance-type sensors are recommended. If no low-cost sensor is available, relative humidity should be considered for deletion from the sensor suite at a given site. 
THIS PAGE

\section{WAS INTENTIONALLY \\ LEFT BLANK}


The upgrading of the SDAS to modern off-the-shelf hardware is one approach to improving the network which may prove cost-effective, since:

- The NSDN system is time-proven, and the major component having reliability problems is the present SDAS.

- The DOE has a large stock of existing instrumentation compatible with the SDAS (and thus its replacement).

- All resident software is time-proven and flexible enough for future applicatlons, with minor changes.

The first part of this section on datalogger requirements will address the present SDAS specifications. New improvements and suggestions will then be discussed. Finally, each of the candidate dataloggers which could replace or upgrade the present system is discussed and conclusions are drawn regarding the future of solar system monitoring.

\section{III.I PRESENT NSDN SDAS CAPABILITIES}

The SDAS specifications and other parameters which are a result of the NSDN remote data monitoring experience are listed below for Mod II and IIa.

\section{NSDN SDAS CAPABILITIES - MOD II AND IIIa}

- Channels: 96

- Storage: $\quad 1.68 \mathrm{million}$ bytes $(210 \mathrm{~K}$ bytes $\pm 10 \%)$ of

$$
\begin{aligned}
& \text { 8K RAM on cassette tape } \\
& 6 \mathrm{~K} \text { ROM for program storage }
\end{aligned}
$$

- Telecommunications:

a. Manual tape retrieval

b. Automatic telephone transmission

- serial transmissinn

- half duplex

- 1200 baud

- binary coding of data

- Programming:

Mod 11 - PROM burn

Mod lla - Hand-held terminal/remote 
- Autostat Capability

- Modular Electronics

- Scan Rates (2):

- 32 second interval

- five minute, 20 second interval

- Accuracy: $0.4 \% \pm 1$ count $5 V$ DC or $100 \mathrm{mV}$ DC, 1023 count resolution

- Time: Relative time clock

- Program Security

- Power: I10V AC

- Environmentel: $32^{n} \mathrm{~F}$. $100^{n} \mathrm{~F}$

5 to $80 \%$ relative humidity noncondensing

As originally deployed, the NSDN was designed to monitor the performance of a certain percentage of solar demonstration sites for the U.S. Department of Energy (formerly ERDA). The Solar Demonstration Act of 1974 gave the authority to pursue a National Solar Data Program, of which the NSDN was a significant part.

IBM Corporation, under contract with the U.S. Department of Energy and the National Aeronautics and Space Administration (NASA), developed a Site Data Acquisition Subsystem (SDAS) for use on the NSDN project.

The SDAS was designed to collect data from sensors located on residential or commercial buildings using solar heating and/or cooling systems. The SDAS collects the data obtained from sensors located on the solar heating and/or cooling system, processes the data into a suitable format, stores the data for a period of time, and provides the capability for either telephone retrieval by the central Data Processing System (CDPS) or manual retrieval of the data for transfer to the central site. The unit was designed so it did not degrade the operation of the solar heating/cooling system which it was monitoring.

A functional block diagram of the SDAS is shown in Fiqure 2.

The SDAS performs the following functions:

- Scans the input sensors, multiplexes and conditions the input data into a digital data format

- Stores the data for later retrieval by the CDPS

- In response to an interrogation by telephone from the CDPS, transmits the stored data to the CDPS. 


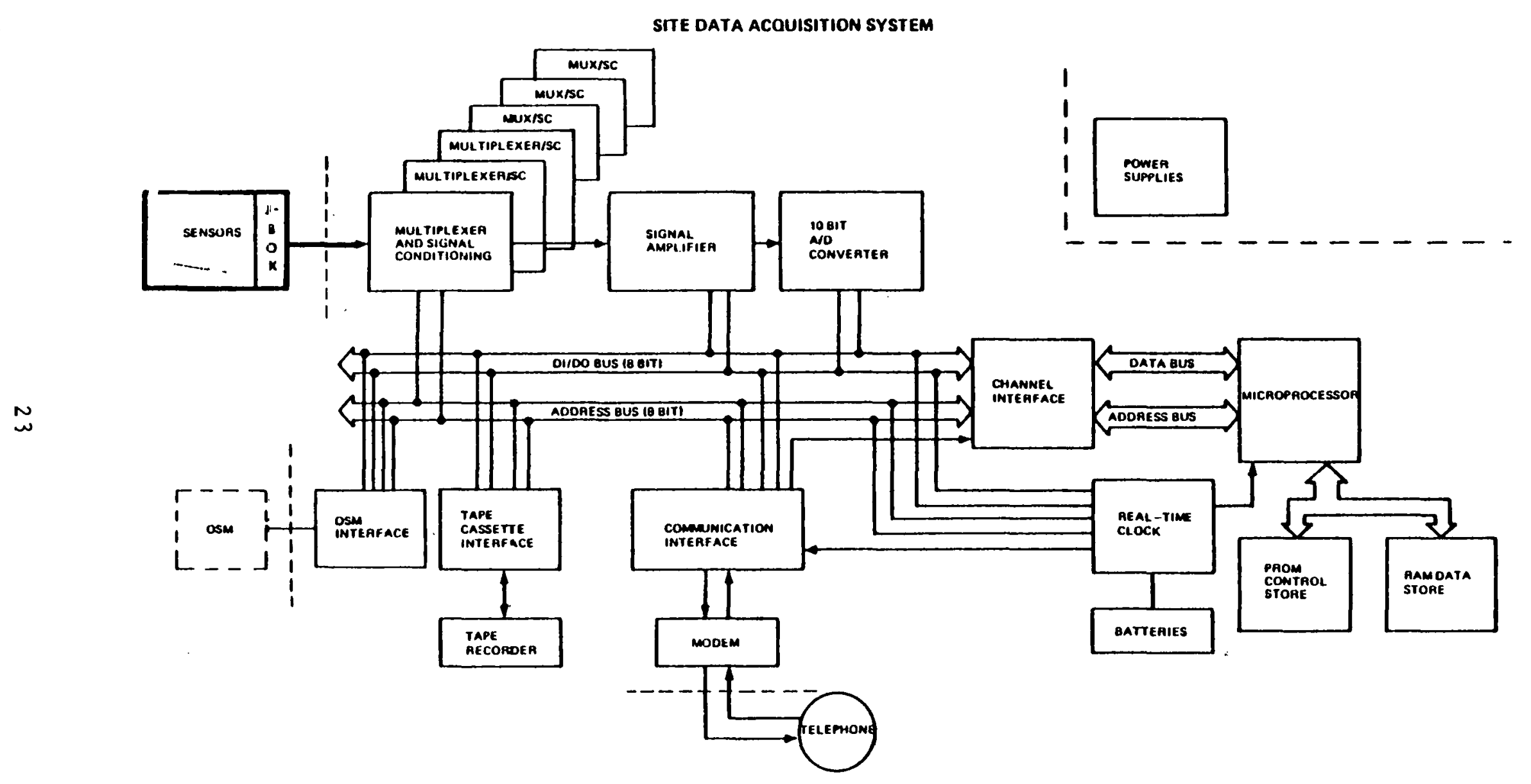

Figure 2. SDAS Functional Block Diagram 
The data to be transmitted to the CDPS is encoded for transmission within the SDAS and transmitted over standard voice-grade 1200 baud telephone lines. Time, synchronization, and error-detecting codes are added to the data to aid the CDPS in error detection, formating, and processing of the data from the SDAS.

The CDPS has a command/response interface with the SDAS to prevent unauthorized access to the SDAS. The SDAS provides codes which enable the CDPS to detect the start and end of records and the end of a file of data being transmitted.

Three versions of the SDAS were used, Mod I (48-channel maximum), Mod II (96-channel), and Mod Ila (96-channel with remote programming and on-site display).

The Mod II and IIa SDASs are the versions in use at the time of this study. The Mod lla differs from the Mod ll in the following respects:

\begin{tabular}{lll} 
& \multicolumn{1}{c}{ Mad II } & Mnd IIa \\
Programming & PROM burn & Hand-held terminal \\
Display & $\begin{array}{l}\text { None, requires on- } \\
\text { site monitor specific } \\
\text { to SDAS }\end{array}$ & 2-channel LED
\end{tabular}

Tape Deck

St andard

Upgraded

The present IBM SDAS has the full range of telecommunications capability as 1 isted on Pages 21 and 22. Error checking is by $\mathrm{BCH}$ (Bose-Chaudhuri-Hocquenghem check byte).

Idealized specifications for a candidate replacement remote datalogger are listed below.

\section{REPLACEMENT REMOTE DATALOGGER REQUIREMENTS}

- Channels: 96

- Storage: 3 days $(82,944$ data points) by solid state

- Telecommunications:

- serial transmission

- half duplex

- 1200 baud

- binary coded data words preferred over ASC II

- error checking by checksum or better

- Remote Program Downloading 
- Powerfail Auto Restart

- Program Security

- Modular Electronics for easy maintainability

- Nema I Enclosure

- J-Box or detachable terminal card

- Two RS232 or IEEE 488 output Ports

- Scan Rate: 96 channels per five minutes with selected channels scanned every 30 seconds

- Accuracy: $\pm 0.4 \%$ of full scale $\pm \frac{1}{2}$ bit@5V DC and 100mV DC

- Time: Real time clock with battery backup

- Program Security: Battery backup for four hours or PROM

- Power: lloV AC

- Environmental: $\quad 32$ to $100^{\circ} \mathrm{F}$

$$
5 \text { to } 80 \% \text { relative humidity noncondensing }
$$

- Analog to Digital: 10 bits

The new datalogger should have solid-state memory, preferably nonvolatile. The requirement for solid-state memory is a result of a high failure rate on the present SDAS cassette tape recorder. Also, the present SDAS tape recorder contributes significantly to data errors during transmission.

The present SDAS maintains the program on a PROM or EPROM. This has worked well but leaves no flexibility. The new datalogger should be remotely reprogrammable with some form of battery backup for the program.

The accuracy of the present SDAS is marginal when measuring small temperature differentials. The specification on the list of the present SDAS specifications on Pages 21 and 22 should be exceeded easily by the newer machines. Also, the A/D resolution of 10 bits should be increased to 12 or 14 bits in the newer machines.

The other requirements shown for the present SDAS have not changed because they have been time-proven.

The enclosure or packaging of the dataloggers chosen for monitoring is also of importance. The present NSDN SDAS uses a sealed metal case, approximately 26 inches by 20 inches by 14 inches, to contain all of the electronics. This device is wall-mounted below a standardized junction box or J-box, to which all of the sensor wires are routed. The SDAS/J-box combination is shown in Figure 3 . 


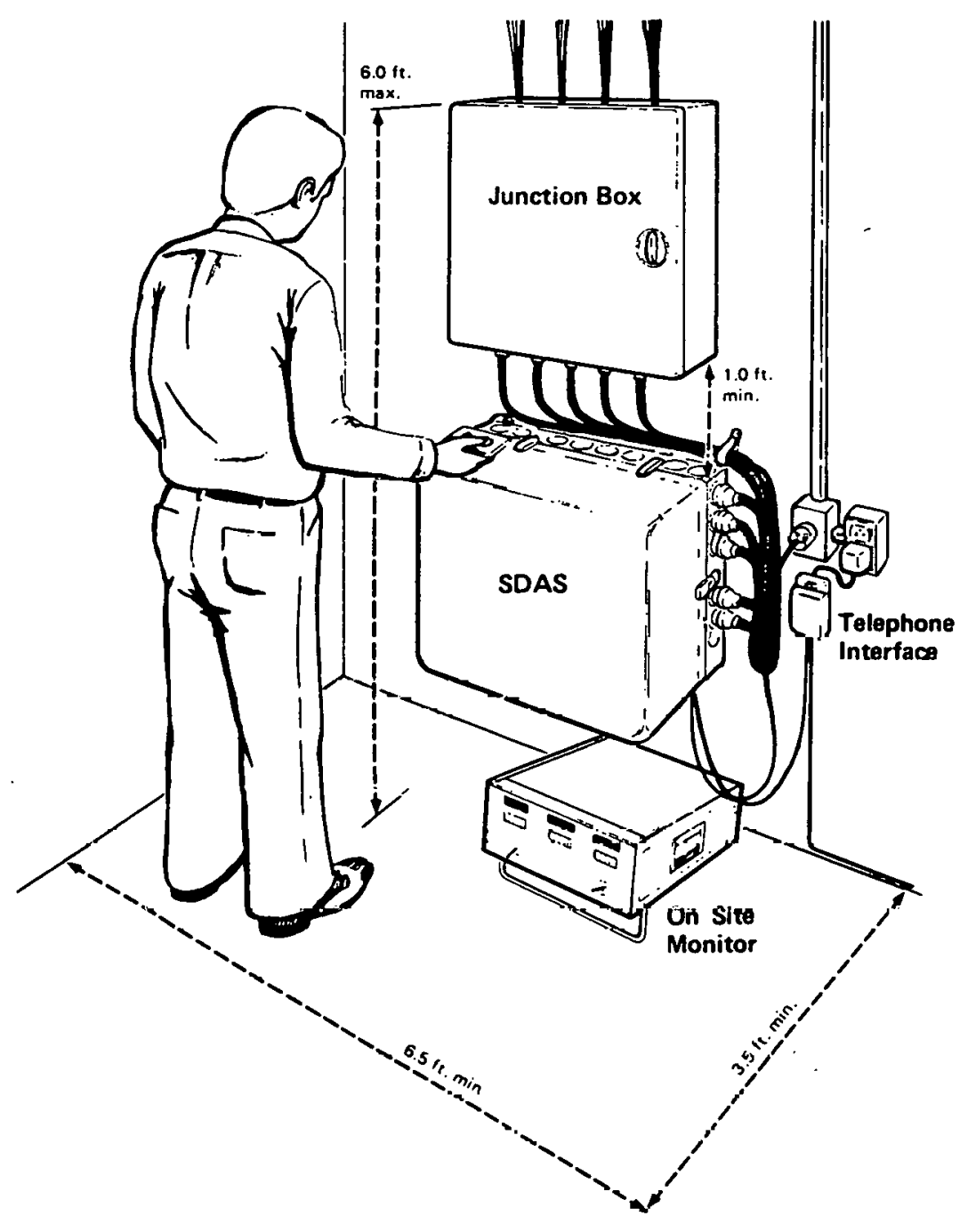

Figure 3. The SDAS/J-Box Configuration

The newer dataloggers are generally packaged in bench- or rackmounted enclosures, with wiring termination at the rear or front face of the device. Some configurations may have several components (such as datalogger, computer, modem, etc.), which probably should be encased in another enclosure to prevent tampering and for safety reasons.

Some of the new requirements are discussed in more detail in the next section. There are also some additional characteristics which were not included in the listing of the present SDAS specifications (on pages 21 and 22 ), because they are considered more optional. 
Future monitoring will be undertaken with the following constraints:

1) Cost - Since overall budget levels for solar and conservation have been reduced to reflect a shift from governmentsupported research to private sector research, costs will necessarily be held to a lower level, per site, than in the past.

2) Accuracy - While accurate data is always the goal, reducing the cost of the datalogging system should not result in a decrease in accuracy, because of technological improvements made in the last 10 years.

3) Usability - The data must be detailed and relevant to the potential users' needs (stilla difficult group to define, but largely consisting of academic researchers, product developers, and the architectural/engineering community), yet be sufficiently summarized for overall program-level decision-makers to absorb.

Vitro corporation feels that future improvements can be made to meet these three criteria, and some suggestions and ideas are presented in the next sections.

\section{Cost Reduction}

The overall costs of monitoring a solar site break down into these categories:

- Hardware costs - The costs of procuring the on-site datalogger, the communications hardware, sensors, telephone installations, wire, etc.

- Setup costs - The costs of setting up the data system, both on-site and at a central location, basically a labor charge for contractor labor to install probes, etc., and labor to checkout the system satisfactorily.

- Maintenance costs - Labor and travel to repair malfunctioning systems.

- Ongoing analysis - Labor and computer charges relating to the on-going periodical analysis, usually labor by degreed professionals. Production of final reports or compilations is also in thls categury.

- Closeout cost - The cost of removal and/or salvage of the

Hardware costs are difficult to reduce if the overall specifications of the present NSDN are retained. The dataloggers which can replace the present SDAS directly are all in the range of $\$ 7,500$ to $\$ 15,000$, 
based on limited volume purchase quotes. Sensor costs are also difficult to reduce if all new sensors are required for each site. A pool of existing sensors such as the NSDN sensor reserves can reduce initial cost, but these sensors are aging and require periodic recalibration by the factory or independent metrology laboratories.

Significant hardware cost reductions appear when:

- Low-cost solid-state sensors are used.

- Low-cost, simpler A/D conversion modules are used to convert the sensor readings to a digital signal.

- Small, portable, on-site computers are used to control the $A / D$ converters and process and stule lle dald rur retrieval.

More of these low-cost systems will be deployed in the future.

Setup costs increase when personalization increases. Modular systems, with "clip on" sensors and fewer sensors would reduce setup time. Also, a number of different calibration checks run on the NSDN SDAS will be eliminated using the more modern dataloggers. The personalization of the present NSDN SDAS requires PROM burning or software PROM-programming, tailoring the signal conditioning section of the SDAS with sensor-specific microboards, wiring of a complex J-box or junction box, and programming of the CDPS with individual calibration information for each sensor.

Newer dataloggers provide input cards.or input modules designed for sensor hookup (eliminating the J-box), and use software programming of the logger (usually quite simple) to tailor the datalogger to the site configuration without hardware modifications. These changes also save time and money.

Maintenance costs can be reduced by:

- Solid-state storage - By replacing the tape deck or disc drive on-site, a significant amount. of downtime could be eliminated through the reduction in the number of moving parts associated with operation of the datalogger. Solidstate memory (RAM, bubble, etc.) is inherently more reliable (but volatile in some cases) than tape drives or disc drives.

- Field swap of bad boards - This capability will reduce maintenance time. Presently, both boards and components are swapped.

- Remote programming - This capability will reduce both setup and regular maincenance costs. Changes can be handled from a central facility, often eliminating a site visit. 
Ongoing analysis can be a major portion of the costs of operating a data network. Analysts costs are a function of the amount of data received, the number of problems encountered, the depth of analysis required, and reporting requirements.

One of the major changes to the overall system which would reduce costs would be the tiering of scan-level engineering unit data to hourly averages in the field, and transmittal of these hourly averages (both of sensor readings and some mathematical calculations) back to the central facility. Some detail and thus some accuracy may be lost, and sensor problems may go unnoticed, but major reductions in transmission costs and time, analysis costs, and processing costs would be gained.

Retrieval of scan data does have some advantages, however, and should not be overlooked. These advantages include identification of sensor anomalies, analysis of system dynamics, and reprocessing capability not available to hourly data transmission schemes. The remote programming capability of the newer dataloggers could provide hourly data, but also scan data on an as-needed basis for in-depth systems analysis of dynamics, sensor problems, etc.

Mathematical calculations performed at the site are also an exciting development in the datalogger field. In fact, some systems provide a wide range of calculations, functions, and other mathematical operations with little additional cost over the basic units.

\section{Accuracy}

Experience has shown that the NSDN can achieve accuracy of less than \pm six percent in the field for accuracy relating to the resolution of liquid site energy flows. Air sites have a $\pm 20 \%$ accuracy, since energy flows at air sites are much harder to resolve.

The error elements of the NSDN data system are categorized into three major groups. These are the sensor error sources, the site Data Acquisition Subsystem (SDAS) error sources, and the computational error sources. Each of these areas is briefly discussed below.

Sensor errors are defined as all error sources arising between the point of measurement and the input to the SDAS. Sensor errors are of two types. The first type is inherent sensor error. These errors are independent of the installation of a sensor at a particular location. The sources for quantifying these errors are manufacturers' references and laboratory tests conducted at the manufacturers' facilities.

The second type of sensor error is "in-situ" or location error. These errors are specific to the sensor location, sensor wiring, installation technique, and to the state of the system where the measurement is made. 
In general, sensors for all sites have been installed in accordance with manufacturers and National Bureau of Standards (NBS) standards, in order to minimize errors due to sensor location.

SDAS errors are defined as all errors propagated in the site Data Acquisition Subsystem.

The sources of SDAS accuracy data are available. An unpublished report details the results of testing performed at Argonne National Laboratory (ANL). Error numbers related to the variation of regulated voltages within the SDAS from several sources were established and found to be less than $0.05 \%$ in most cases. A significant area of concern was long-term drift of readings at many sites. Line voltage variation, temperature regime of the SDAS, and repair/replacement were found to have less significance. Secondly, side-by-side testing of a fully deployed sensor/SDAS system resulted in performance factor accuracy within \pm six percent of reference measurement.

Computational errors are propagated from application of analytical techniques to the data stream, and include rounding errors, data gap errors, and sampling rate errors.

Estimation of actual computational errors was accomplished using computer simulation to determine round-off and sampling rate errors, the effect of data gap bridging, and the effect of errors in the measurement of certain constants and auxiliary parameters that affect performance factor computations. The effects of these errors were established by actual measurement at the test sites, data acquired from other sources, and from analytical techniques.

Data is occasionally lost at NSDN sites for a variety of reasons. Values for missing data elements are created by a data bridging routine. There will always be some error associated with the estimation process.

For data losses of $10 \%$ or less, the performance factor accuracy is not significantly affected. Most errors are less than three percent. The significant exception is change in stored energy, which is very sensitive to data loss.

Some performance factors are stable with relatively large data loss. Calculation of overall system performance generally remains stable with less than $20 \%$ data loss.

The replacement datalogger will have better accuracy and noiserejection specifications than the present SDAS. Therefore, overall system accuracy should improve with the replacement. Appendix $B$ presents a comparison of accuracy (percent of full scale, $A / D$ resolution) and noise rejection ( $i n$ terms of common mode rejection in d $B$ ). 
Usability

While no consensus exists as to the most useful format for transfer of information from the data monitoring project to the intended users, certain basic factors remain constant.

- Usable data for mainframe or microcomputer applications should be a product for researchers.

- Generalization based on wide overview-type results will be of more interest to program-level decision-makers.

- Product developers want to know about component performance and how that performance affects systems.

Each of these requirements represents a different type of data product, so format requirements for the data products should be well thought out ahead of time.

The use of microcomputers (such as the IBM-PC, etc.) will certainly become more prevalent in future analysis schemes and in research and development. Bear in mind, however, that the volume of data required for detailed analysis (assuming a scan-level data collection scheme) will probably overwhelm the capability of a typical desktop micro. (See Section IV for discussion.)

\section{SUMMARY}

What we have tried to illustrate in this section are a number of observations we have made concerning the overall philosophy behind a future monitoring system. A tradeoff between cost, accuracy, and usability of the system and its resulting data must be considered and weighed against the intended use of the data.

\section{3 DATALOGGERS BY MANUFACTURERS}

As stated earlier, this survey considered 36 datalogger manufacturers and 62 various models from those manufacturers for SDAS replacement and/or total system upgrade. The manufacturers and models investigated are 1 isted in Appendix $A$ along with addresses and telephone numbers.

The process used to screen the dataloggers for suitability was a two-s.tep procedure. The standard of comparison was and is the present IBM SDAS (Site Data Acquisition Subsystem).

The first step was a coarse filter wherein the dataloggers were examined for their ability to monitor 96 channels, be remotely accessed by telephone (modem capability), and to perform analog voltage measurements. Many of the candidate dataloggers failed on number of channels and modem capability. 
The remaining dataloggers were then compared to the SDAS and to some additional characteristics which, should be available on the next NSDN datalogger.

The following pages of this section contain a discussion of the dataloggers which are considered as candidates for the SDAS replacement. A detailed comparison of each datalogger's characteristics compared to the new SDAS requirements is shown in Appendix B.

The Sëries MX Maxilogger is manufactured by A.D. Data Systems, Inc. This machine can handle up to 1,000 channels, but has a solidstate memory capacity for only 1,000 data points. The datalogger's telecommunications capabilities are not up the the SDAS standard because there is no provision for error checkilig. The data must be transmitted in ASCII characters. The accuracy is approximately the same as the SDAS. Most other requirements are similar to the SDAS except this datalogger can withstand up to $122{ }^{\circ} \mathrm{F}$ and yu\% relarlve humidity. The datalogger offers an improvement in flexibility because it can be remotely programmed.

The Accurex Autocalc has a 256-channel capacity and four days of RAM storage capacity. It has good telecommunications capability but can offer no error checking. Data transfer is by Ascil characters. Although the analog to digital resolution is 14 bits, the accuracy is similar to the SDAS. Scan rate is 20 channels per second. Environmental capacity exceeds the SDAS because the Autocalc can survive up to $140^{\circ} \mathrm{F}$ and $90 \%$ relative humidity. Perhaps most impressive, are all of the built-in mathematics options. The ability to do averaging, maximum and minimum, and energy flow calculations at the bile cuuld greatly rclicve the burden on the mainframe. Also, this machine can be programmed remotely from the RS 232 port, and it can accommodate puise counting.

The Campbell Scientific Company has two datalogger models, the CR7 and $21 x$, which would make suitable SDAS replacements. Since the CR7 and $21 x$ are similar except that the CR7 is more accurate, this discussion will be 1 imited to the $21 x$. The $21 x$ datalogger is a newer Campbell Scientific machine which offers a better telecommunications package. Basically, thls machille lids 16 channels which can be multiplexed to 32 channels on each channel, so there is ample channel capacity. The machine is fully battery-powered with a llov charging circuit as backup so all capabilities remain active for 10 days in a power failure. The $21 x$ has a complete telecommunications package including checksum error checkilig and binary data (two bytes per data point) transmission. The datalogger has 14 bits of A/D conversion with a $0.03 \mathrm{microvolt}$ resolution in the $5 \mathrm{mV}$ range. Two hundred and fifty channels can be scanned every second. A substantial mathematics package is available for calculating averages, maximums and minimums, and energy flows. Solid state memory is sufficient for 55,000 data points only. This is approximately two days. The datalogger can withstand temperatures from $-13^{\circ} \mathrm{F}$ to $122^{\circ} \mathrm{F}$, and zero to $70 \%$ relative humidity. One feature which is unique to Campbell Scientific is the availability of a complete telecommunications system for a host IBM PC computer. 
The Crodata M1600L has a 100-channel capacity and some telecommunications capability. There is no error checking or program download capability. Also, there is no solid-state memory; a cassette tape unit must be used and this has a 66,000 data point capacity. Accuracy is very good at $\pm 0.1 \%$ of full scale. The scan rate is 50 channels per second. Environmentally, the machine is designed for temperatures from $15^{\circ} \mathrm{F}$ to $120^{\circ} \mathrm{F}$ and zero to $95 \%$ relative humidity. Pulse input data can be sampled.

The Cyborg Isaac 2000 is designed to be used with an IBM PC beside it. This datalogger cannot stand alone, but, because of the computer host, much greater flexibility can be obtained. Storage is very large with a fully configured IBM PC. Complete telecommunications with error checking is possible. The ability to perform complex math calculations is extremely good, so data can be averaged, linearized, compared, and many energy flows can be calculated. The datalogger accuracy is very good at $\pm 0.05 \%$ of full scale. There is a 12 -bit analog to digital conversion. Scan rates down to 0.1 second are possible. Environmentally, the datalogger can operate from $50^{\circ} \mathrm{F}$ to $104^{\circ} \mathrm{F}$.

The Doric Digitrend $(B) 235$ datalogger is a rack-mount or benchmount microprocessor-based datalogger manufactured by Doric Scientific Division, Emerson Electric Company of San Diego, California. The device has a 100-channel input capability, capable of handling thermocouples ( $T, B, J, K, R, S$ ), RTDS, volts, millivolts, milliamps, ohms, digital inputs (optional), status, and alarm capability. One unique feature of the Doric is the Front End Module (FEM), which allows installation of the FEM near the sensors, and connection of the FEM to the mainframe via inexpensive 4-conductor digital cable. The unit uses a 16-bit A/D converter. A front panel provides for program entry and 7-segment LED display of values. A thermal printer is standard, as well as a fully rate switchable RS 232-C Serial 1/0 port capable of $110,300,1200$, 2400,4800 , and 9600 baud. The datalogger has fully programmable character fonts, full or half duplex, line or block control, header or trailer data, etc. Internal storage is not available. A tape drive or other storage medium is required.

The Esterline-Angus PD2064 has a capacity of 96 channels, but does not have solid-state storage. A cassette tape would be required for storage. The datalogger accepts all of the common sensor inputs - analog, thermocouples and RTDs. Telecommunications is available through an RS232 port. However, error checking is not available without modification. The machine has an accuracy of $0.25 \%$ of span. Battery backup for the program is an option. The scan rate is 22 channels per second.

The Fluke Model $2280 \mathrm{~A}$ datalogger is a data acquisition, reduction, and recording system. It may be configured to accept analog or digital data inputs, or a combination of the two, from a variety of input devices. Input data may be processed and mathematically manipulated in many ways, depending of the desired output. Both analog and digital inputs may be monitored and the $2280 \mathrm{~A}$ will 
provide alarm outputs if limits selected by the user are exceeded. The $2280 \mathrm{~A}$ mainframe services a combination of up to 100 programmable analog channels and/or 120 digital channels. It is expandable through optional extender chassis, up to 1,500 channels. The basic unit is contained within a mechanical housing designed for standard 19-inch rack mounting. It includes full front panel controls, a 40-character alphanumeric display, a 40-column printer, a nonvolatile system memory, and a powerful CPU. It accepts power from AC power lines or from a 12-volt battery. All internal system communications are digital. No analog signals are sent through cables. Thus, the $2280 \mathrm{~A}$ is able to provide excellent accuracy and exceptional system integrity. A 64,000-count (16-bit) A/D converter is used, providing high levels of accuracy. The optional Cartridge Tape Drive (Option -214) supports high speed data recording, as well as easy program storage and recall. The program in a $2280 \mathrm{~A}$ may be saved indefinitely on tape, or used to program another 2280A. In case the power tails or the system is slmply curned orf, all prugram memory in the $2280 \mathrm{~A}$ is battery maintained for 30 days. The system clock will also continue to run during that time. The $2280 \mathrm{~A}$ has extensive computational power that makes possible very complex data reduction and control strategies. The standard $2280 \mathrm{~A}$ configuration al lows the programmer to use different combinations of addition, subtraction, multiplication, and division to convert the results of a channel measurement from a raw number to a relevant value. In addition, pseudo channels can be programmed with a math expression that contains readings from other channels besides itself. Thus, averaging and other interchannel computations are easily performed. RTD linearizations can be tailored to the characteristics of the probes.

The Hewlett-Packard 3056DL Datalogger is a system which uses up to two HP3421A Data Acquisition and Control Units with the control unit being the HP8SF microcomputer. Up to 60 channels can be maintained using this system. The $3421 \mathrm{~A}$ has a 300,000 count resolution, full-scale accuracy of $0.01 \%$ DCV, a I $\mu V$ sensitivity, and $120 \mathrm{~dB}$ Common Mode Rejection at $50 / 60 \mathrm{~Hz}$. Digital input is also available. The 3056DL system can handle 17 functions, including DC volts, RTDs (two-wire, four-wire), AC volts, ohms, frequency, 2.216 thermistor, J, K, T, E, R, S thermocouples, 4-20 mA, and activation. Some software development will be required to provide totally remote operation of this system. Since the HP85F is programmed in HP Basic, this development should not be a major problem. Some deveopment work on an Apple II/HP3497A combination (similar to the 3421A/ HP85 combination) has been done at Vitro Corporation. No battery backup is available. Also, the unit requires a rack or mounting in a separate enclosure, since the system consists of two rack-mountable data acquisition units and one desktop microcomputer.

The CompuDAS 3 is made by ITHACO and features the Intel 8086, 16bit microprocessor. There are two sizes: a 120 -channel and a 420channel chassis. There is also an eight-bit datalogger built around the $280 \mathrm{microprocessor.} \mathrm{Solid-state} \mathrm{memory} \mathrm{is} \mathrm{available} \mathrm{in}$ $32 \mathrm{~K}$ bytes per card, either volatile or battery backed RAM. Only the CompuDAS 3 can support enough memory for the SDAS replacement. 
There will be a $128 \mathrm{k}$-byte memory card in the future. Communications are handled via two RS232 ports with an expansion card for four more RS232 ports if needed. Note, an external modem would be required for telecommunications. The full range of analog sensor inputs is supported by a 30-channel card. There is room for three to four cards in the small chassis, depending on memory and other allocations. Pulse counting is available, but with only four channels per card. The CompuDAs dataloggers are fully programmable in a basic language specific to datalogging called "DABIL 1." The DABIL I was developed by ITHACO from Dartmouth Basic. The programmable features of these dataloggers provide unusual flexibility for the user. In this specific application for a remote data network, error checking and telecommunications "handshaking" will be greatly facilitated. Due to the multiuser capability of the internal datalogger, the machine continues to scan sensors during a data dump. The CompuDAs can resolve to $0.001 \%$ of full scale. It has a 12-bit A/D resolution and can scan 20 channels per second.

The Digi Scan IOC is manufactured by JEW Instruments. The Digi Scan has a 128-channel capacity, but only cassette tape storage. Telecommunications are supported, but no error checking procedure is available. This datalogger has a $15-b i t$ A/D conversion process and resolution to $0.1^{\circ} \mathrm{F}$. The program is retained in EEPROM, so battery backup is not needed but remote reprogramming is fully possible. The scan rate is 16 channels per second per card, so a fully configured datalogger could scan 128 channels per second. There is a pulse counting input option as well as a mathematics package option. The datalogger will tolerate temperatures from $32{ }^{\circ} \mathrm{F}$ to $122^{\circ} \mathrm{F}$ and rela.tive humidity from zero to $90 \%$.

The Monitor Labs 9350 Datalogger is a suitable candidate for SDAS replacement, although internal solid-state storage capacity requires use of an auxiliary tape drive if scan level data is to be collected. The unit provides for the ability to input up to 1,040 channels of analog data (with the optional 1,000-channel expansion chassis) plus 80 channels of digital data (TTL or contact closures). An alarm-level can be set, data averaged, calculations performed (using a sophisticated mathematical processor option), and output to the printer and/or external tape drive. The unit is fully programmable on an RS232 serial interface, and can be interrogated remotely. The 9350 program is 27,000 words in length, stored in $112 \mathrm{~K} \times 8-\mathrm{bit}$ UV PROMS on the memory expansion board. Once programmed at the factory, these UV PROMS retain their memory status unless exposed to UV light. A $16 \mathrm{~K}-\mathrm{block}$ of Static RAM is used to provide a scratch pad (calculation space) and to hold 20 channels of setup data. EAROM storage system provides for program storage up to 99 years without battern backup (EAROM is Electrically Alterable Read Only Memory). The unit uses a $\pm 32,767$ count $(15-b i t)$ A/D connector with $1 \mu \mathrm{V}, \pm 0.10^{\circ} \mathrm{F}$ or $0.10^{\circ} \mathrm{C}$ resolution. Common mode rejection is greater than $120 \mathrm{~dB}$ with $1 \mathrm{~K}$ ohm at $50 / 60 \mathrm{~Hz}$. The unit accepts $\pm 30,000 \mathrm{mV}, \pm 300 \mathrm{mV}, \pm 3 \mathrm{~V}, \pm 10 \mathrm{~V}$ plus overranging. Auxiliary cards provide thermocouple reference junction, RTD capability with screw lug terminals at the rear of the unit. 
Monitor Labs also provides a fully operational HERS (Historical Environmental Recording system) which is a distributed data processing and telemetry system for acquiring, reducing, validating, and processing data for environmental data networks operating under U.S. EPA (Environmental Protection Agency) criteria. This system collects hourly data and could be adapted to NSDN use. 
SECTION 111

\section{COMMUNICATIONS WITH A REMOTE DATALOGGER}

When the National Solar Data Network (NSDN) was established over ten years ago, there were no dataloggers with remote communications capability. The IBM Corporation designed the system used by the NSDN to a specification which can be more easily reached today.

The datalogging system concept was referred to in Figure 4. This section deals with the telecommunications aspects of a datalogging system. The sequence of operations during the telecommunications phase is shown in Figure 5. This process is automatic once started. Depending on the results of the auto-calls, the sites not responding should be called manually.

The Site Data Collection Process is diagrammed in Figure 6. Note that there is a site identification requirement, an error checking procedure, and a datalogger restart requirement. The present NSDN error check procedure is a manual one whereby the operator checks the status results to determine the number of errors. If errors are high, the procedure is repeated by a manual call to the site.

The key telecommunications factors to consider are:

- Does the datalogger have modern capability?

- Can the datalogger perform "handshaking" functions?

- Does the datalogger generate a checksum or some other form of error checking protocol?

The dataloggers which attach to small personal computers generally accomplish these functions quite nicely if the computer has the modem capability and if the user can develop the necessary software. The stand-alone datalogger may or may not have all of the capabilit ies listed above and, since they are not usually programmable at the machine instruction level, there is no way to overcome the deficiency.

The biggest shortcoming with most stand-alone dataloggers is in their ability to enable error detection by the receiving computer. Many machines do not have any error checking protocol. The other common shortcoming is the lack of a "handshaking" or interrupt driven communications protocol. For example, the present NSON datalogger has no handshaking ability. Once data transmission begins, it continues until the data tape has been completely emptied.

The lack of "handshaking" protocol does not pose a serious problem, because the entire dataset can be retransmitted. However, the lack of an crror detection scheile cannot be toleraced. From the 


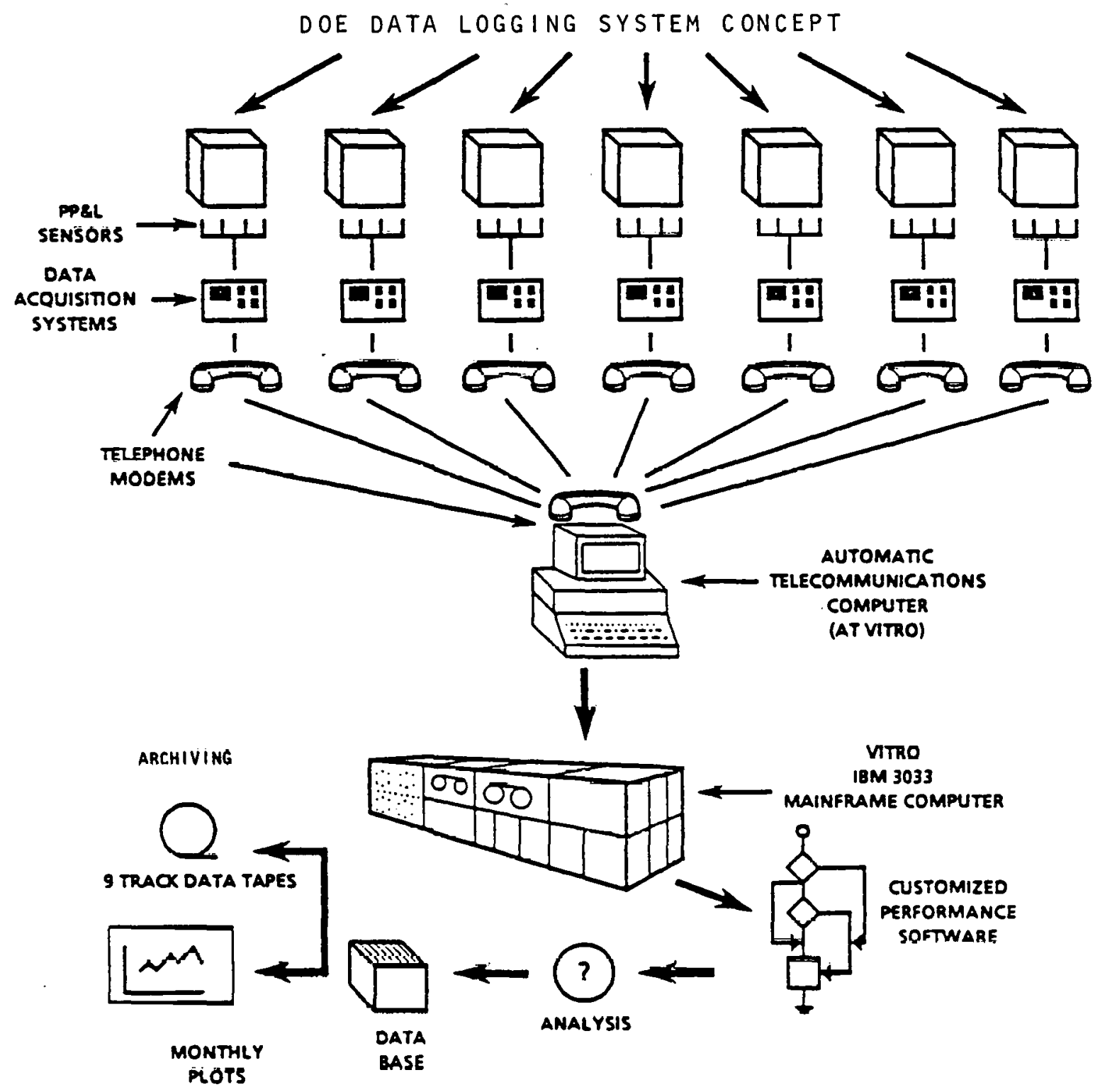

Figure 4. Representation of Datalogger System 


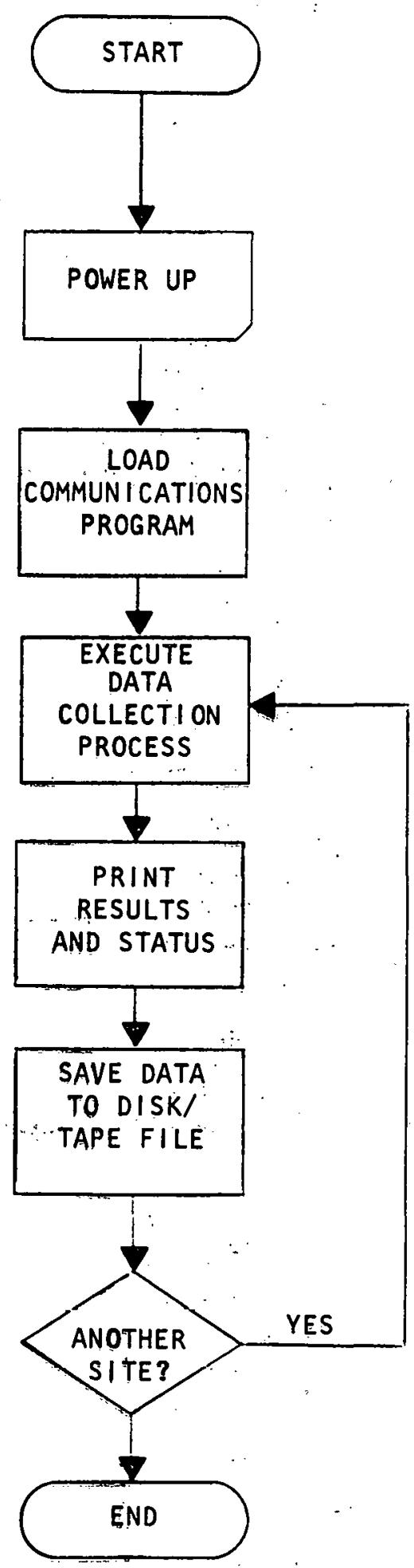

Figure 5. Sequence of Data Collection Operations 


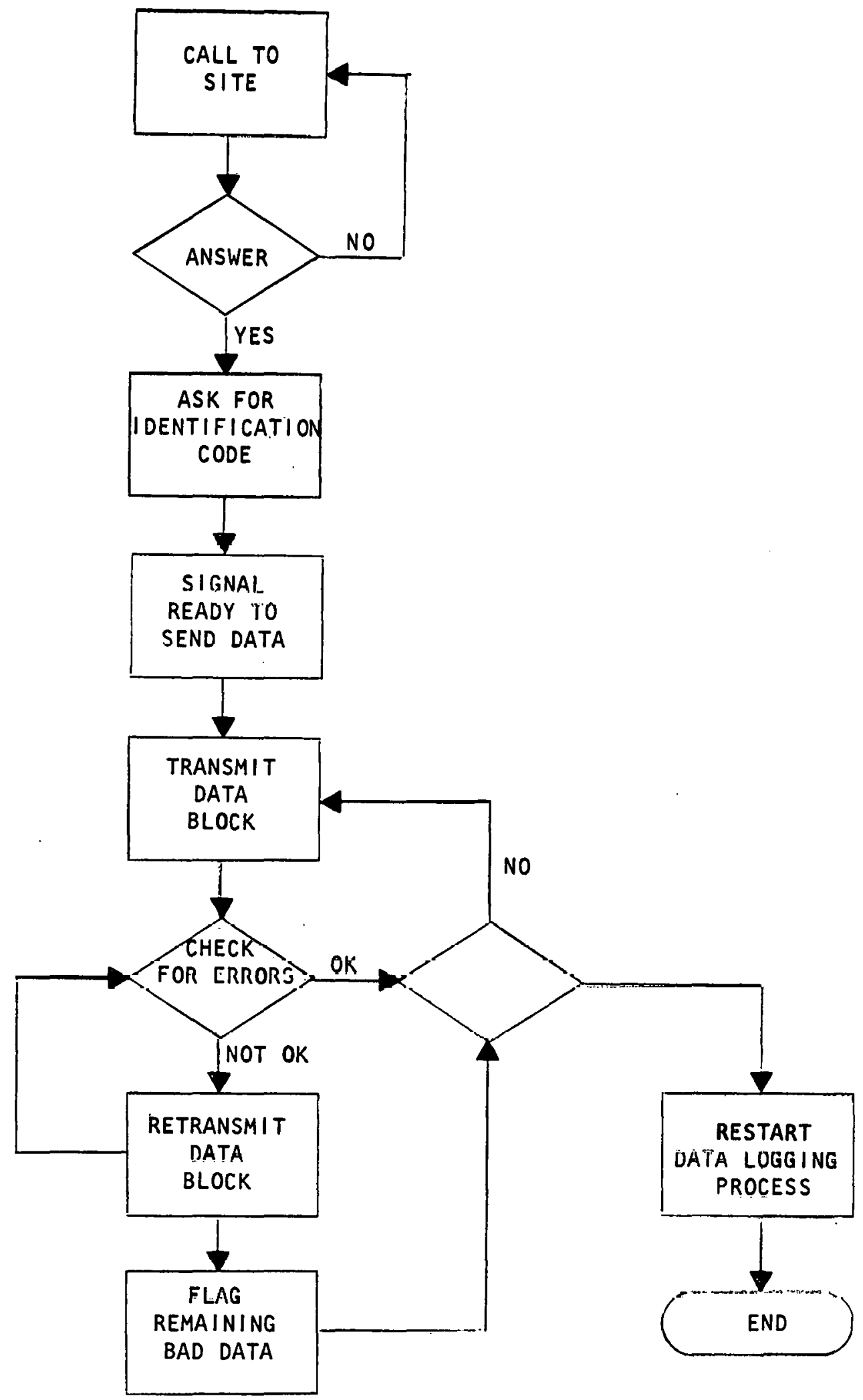

Figure 6. Site Data Collection Sequence 
NSDN experience, a relatively simple scheme like a checksum or bit count, is sufficient. Usually telephone lines are noisy to the point that most data is bad.

Two other important criteria to consider regarding telecommunications are baud rate and data-string length. Most of the dataloggers presently available will receive and transmit at 300 or 1200 baud. (The baud rate refers to the number of bits per minute transmitted.) The 1200-baud rate is essential although higher baud rates may be possible without special leased telephone lines. Faster transmission rates over voice-grade telephone lines are technically feasible. now, but error rates and costs are prohibitive.

The data-string length is important because it will determine the time on-line to each remote datalogger. Most dataloggers being marketed use ASCIl character strings ranging from 12 to 25 characters. (An ASCII character requires one byte or eight bits.)

These long data strings create excessively long data transmission times. For instance, even a 12 -character data string would take 0.08 seconds to transmit at 1200 baud. Fifty channels of data take 4.16 seconds to transmit if there are two header records. Depending on the scan interval, a day's data transmission could take from 100 seconds for 50 channels of hourly data to 100 minutes for 50 channels of one minute data. If many channels of high frequency data are required, then a compressed or binary coded data string must be used. The present NSDN data string is 16-bits long. A short data string does not permit high resolution of the data, so the tradeoff is between telephone call time and data point resolution.

There are several other considerations which must be included in any successful remote datalogger network. These are:

- Auto dial with manual override

- Auto answer modem

- Automatic restart of dataloging after the data has been sent

- Full duplex transmission

- Callup status printout

- Remote program upload or downloading

An auto dial teature should be available on the computer at the central laboratory. Perhaps the auto dial feature is not essential for Just a few sites, but it is highly recommended for more than five sites or when large quantities of data are transferred daily. Programs which have the auto dial feature are available. A program which the Vitro Corporation has used with the IBM PC is "Crosstalk." This program allows the user to create a file with the time to call telephone number, identification procedures, and file name for incoming data. The program also allows a manual 
initiation of the telephone call and subsequent data transmission. Another feature which can be used with an auto dial program is to conduct calls during the night to take advantage of reduced telephone rates.

The second consideration is to be sure that the site dataloggers are connected to an auto answer modem. The Bell $212 \mathrm{~A}$ has been utilized successfully for several years on the NSDN.

The dataloger software should provide for an automatic restart of dataloging after the data transmission has ended, even if the transmission was cut short. This restart is not an essential feature but will make automatic callup and data transmission more fail-safe. The automatic restart program should start writing data at the end of the existing data on the data storage device. If there is an end of file on a tape storage device, this should be written over to prevent lost data. The present NSDN datalogger continues to send data until the End of File (EOF) if there is a line break. When the datalogger reaches an EOF, it just slops and waits for the next command. This procedure does not cause any old data to be lost, but does require that an operator be in attendance during the calling operation.

The haif duplex transmission mode is recommended because it is faster. (During full duplex transmission, the receiving computer echoes the bits back to the sending computer. High accuracy is possible, but with significantly longer call time.) Additionally, most dataloggers do not have the capability of full duplex transmission.

A status printout of the site called is an important accounting device. The call status report used by the NSDN contains the following information:

- Sile liame and number

- Number of bytes or data points received

- Number of blocks and scans with errors

- A call slalus code

- Start and stop time and date

- Number of good daca polnls dild lulal liumber of puints

- Maximum and minimum readings for each sensor

This status report provides the operator with the results of the call and with a quick look at the quality of the data.

Many of today's dataloggers can be programmed either remotely or on-site. This capability is a valuable feature because it permits more flexibility. The datalogging program can be changed easily 
by telephone to meet changes in objectives or accommodate new tasks. The present NSDN dataloger does not have this flexibility. 
THIS PAGE

\section{WAS INTENTIONALLY LEFT BLANK}




\section{CENTRAL FACILITY DATA PROCESSING}

There are two distinct tasks for the central facility computer. First, is the task of calling each site daily, weekly, etc. to retrieve the data. The second task involves processing the data to produce aggregated results which satisfy the original objectives.

The data retrieval task has been dealt with in Section 111 , Communications with a Remote Datalogger, from the viewpoint of the datalogger. The computer at the central facility which did the calling was largely ignored. The communications computer could be a larger personal computer like the IBM PC XT, a mainframe or a dedicated mini-computer like the IBM System 7 , presently used by the NSDN (see Figure 7).

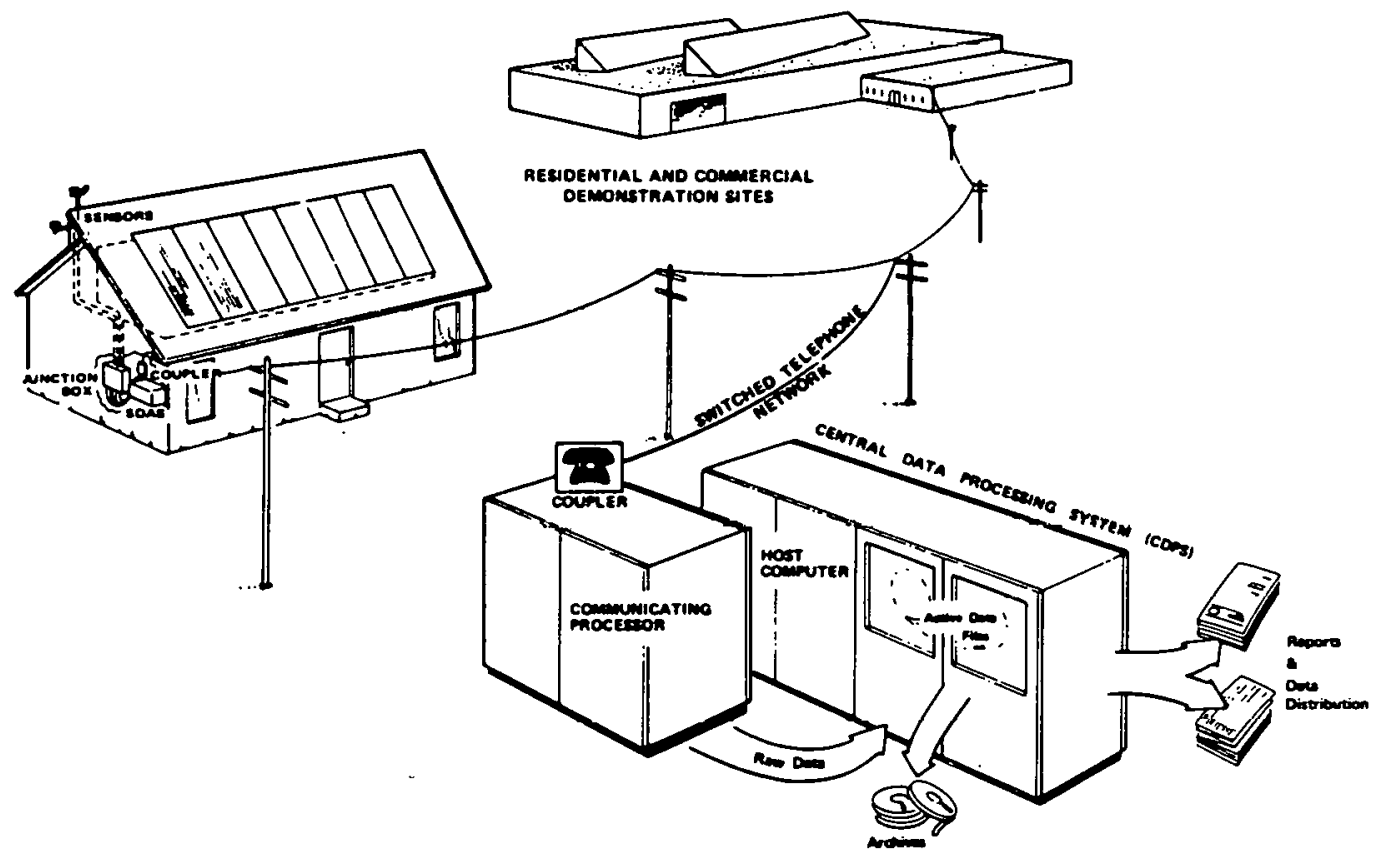

Figure 7. The National Solar Data Network 
The communications computer must be able to automatically call remote dataloggers and must be able to store large amounts of data. The software program would preferably be able to call two or more sites at once, automatically, but with a manual override. More details on the communications procedures are contained in Section lll. The storage space required should also be a criteria for choosing a communications computer.

For example, a data network has 20 remote sites with an average of 40 channels at each site. For this application, data scans are. every five minutes, so each site has a maximum of 11,520 data points a day to transmit and store. This number would increase to 12,096 data points with two header records for each scan. The total maximum number of data points including header records for 25 sites would be 302,400 data points. If the data can be stored in a compressed format of four bytes per data point, then $1,209,600$ bytes or $1,181 \mathrm{ki} l o b y t e s$ of storage are needed for each day's data collection process. However, if the data is stored as ASCII characters of 16 characters each, then the storage requirements jump to $4,838,400$ bytes, or 4,725 kilobytes. This moderately sized data network can generate large quantities of data.

Due to the need for large quantities of data storage, the communications computer must be selected with good data processing speed and adequate internal and external storage. The NSDN System 7 computer only has 64 kilobytes of memory, so the data is transferred to a nine-track tape. A modern microcomputer communications system would be configured with the following hardware and software:

\section{AN IBM PC XT COMMUNICATIONS SYSTEM}

- IBM PCXT with one double-sided double-density floppy disk drive, 256 Kb memory plus a Quadram board with an additional $256 \mathrm{~Kb}$ memory and system clock.

- 20 megabyte hard disk drive

- IBM qraphics monitor and board

- Hayes Smartmodem 1200's

- Epson FX-100 doe matrix printer

- IBM DOS 2.I - Disk Operating System

- Asychronous Communication 2.0

- Crosstalk 16 - telecommunications software 
Depending on the data quantities involved and the calculations required, the communications computer might also do the data processing. However, for networks larger than several dataloggers and for data processing requiring math processing beyond addition, a mainframe computer would be the choice for data processing.

The need for a mainframe computer for data processing is more readily apparent from the following example. Here, each site (25 sites total) creates 12,096 data points per day times 30 days per month, for 362,880 data points per month. With 25 sites in the network, the total number of data points becomes 9,072,000. A typical NSDN solar home system with hot water and space heating load subsystems would have 100 equations to process this data. The processing of 360,000 data points takes only a few seconds on a mainframe, but would take substantially longer on a personal computer. Also, data $1 / 0$ on a mainframe is only a few seconds, but could take hours on a personal computer.

There is one more point to consider if a mainframe is used for data processing. The data retrieved by a micro- or mini-computer must be transferred to the mainframe. This transfer can be costly and difficult if there are many data points. The use of a 1200 baud telephone link is not very practical for a large network collecting data frequently. The NSON uses a nine-track tape because that equipment was most cost-effective when the NSDN was established.

With a nine-track tape, the data transfer rate occurs at 19,200 baud, which is 16 times faster than the 1200 baud telephone line. A direct link via coaxial cable to the mainframe also allows data transfer rates of 19,200 baud. The direct coaxial link would also permit greater flexibility because parts of data files could be transferred back to the personal computer for special projects.. 
THIS PAGE

\section{WAS INTENTIONALLY LEFT BLANK}


This extensive survey of dataloggers produced three very good candidates for the NSDN replacement. These are listed below in order of the author's priority:

\section{- Campbell Scientific CR7 \\ - Monitor Labs 9350 (HERS) \\ - ITHACO COMPUDAS 3}

The Campbell scientific was placed as Number 1 because of the inplace low-cost telecommunications program. Also, the total reliance on battery power makes the datalogger practical for a portable monitoring unit. The CR7 is memory expandable to $40 \mathrm{k}$ bytes, or enough storage for 19,500 data points. Calling time will be reduced to an absolute minimum because the data can be transmitted in binary data words of two bytes each. (This is the same as the present SDAS.)

The Monitor Labs 9350 system is the second choice because of the telecommunications system. However, this telecommunications system is much more expensive than the Campbell scientific system. Also, the Monitor Labs machine has only $16 \mathrm{~K}$ bytes of RAM storage. This is too small for most of the NSDN applications. Communications is in standard ASCII, which is compatible with nearly every computer host but requires longer calling times. Pulse output must be ramped to an analog voltage before the datalogger will read those sensors.

The ITHACO CompuDAS 3 is the third choice because the telecommunications software would require development. However, this machine has larger storage capacity and perhaps more potential capabilities than either of the first two machines. Since the Compudas 3 is a true 16-bit microprocessor, there is much more capacity for implementing real time data processing. This increased capacity could ald analysis and reduce manhours and mainframe computer time.

Cost comparisons are difficult to make because of the numerous options and different configurations available which can accomplish almost any datalogging task. A typical large NSDN active solar system might require the following types of datalogger channels:

$$
\begin{aligned}
& 32 \text { RTD Temperatures } \\
& 15 \text { Analog Voltage } \\
& 10 \text { Contact Closure } \\
& 10 \text { Period of Time } \\
& 8 \text { Pulse Counters } \\
& 75 \text { Total }
\end{aligned}
$$

These channel requirements were used to determine a typical datalogger configuration for the three dataloggers recommended above. 
This configuration was used to establish an approximate price for each datalogger. (The prices were determined from manufacturers' suggested retail price sheets.) Accordingly, the prices for the typical configuration are:

$\begin{array}{ll}\text { Campbell Scientific CR7 } & \$ 8,520 \\ \text { Monitor Labs } 9350 & \$ 9,230 \\ \text { ITHACO CompuDAS } 3 & \$ 16,800\end{array}$

The reason for the much higher price on the ITHACO CompuDAs 3 is suspected to be due to much greater flexibility. However, the large difference in price between the ITHACO CompuDAS 3 and the Campbell CR7 or Monitor Labs 9350 is not likely to result in a proportionally greater improvement in data quality or datalogger reliability. As a further note, the ITHACO CompuDAs 3 is a new machine and may become more cost-effective with time.

During the course of this survey, there were several dataloggers which claimed remote monitoring capability but did not have the channel capacity to merit further review. These dataloggers are mentioned below because there may be some applications where a fewer number of channels would suffice. Usually these dataloggers are less costly. These machines are:

Campbell Scientific $21 x$

Fowlkes Engineering SAM 8.12.4

Kaye Digilink IV

Linscis L8500

Novatech Multiple Channel Data Recording System Piñon Systems SEMS-II

The dataloggers surveyed and recommended in this report are intended to be a part of some future Department of Energy data monitoring network. As such, the report touches briefly on the types of sensors currently used by the NSDN and the telecommunications and data processing requirements for a small (25 sites) remote data network.

Given that some form of field monitoring will be undertaken in the future, it seems appropriate at this point to add some recommendations as to where these efforts might be directed. There are three monitoring concepts which are feasible and can be accomplished within the framework of the recommended datalogging and data processing systems set forth above. These are:

- Cradle-to-grave case study

- Small-scale network like NSDN

- Portable, low-cost system 
The cradle-to-grave case study concept would utilize the scaled-. down NSDN concept. However, unlike the demonstration program, these programs would involve data gathering or monitoring from the preliminary design through the first two or three years of operation. A final report would describe the design and installation process and the operational performance of the system.

Specifically, the report should contain exact cost information from estimates through actual expenditures, problems encountered and their solutions, with these categories grouped as site-specific and system generic, and then acceptance test data and operational performance data. Objectives of this type of study would be to document the design process, understand the cost parameters, describe and document the system installation, and determine initial and continuous operational performance parameters.

The small-scale remote monitoring concept would be suitable for special projects like the packaged space heating project. Systems with new and unusual components or applications would be monitored for one or more years to determine if field performance bears out the model expected performance. The final report would contain the field-measured performance parameters and comparisons to the expected performance.

The low-cost portable monitoring concept would be used to obtain limited performance data for a large sample of sites. The monitoring system would contain a portable datalogger with primarily nonintrusive instrumentation for a quick look at a system to determine the performance characteristics of the installed system. A flow meter and differential temperature measurement would be necessary for critical energy flow parameters such as collected or delivered solar energy. A low-cost self-contained battery-powered monitor could be left at the site for monitoring run time, solar energy incident on the array, and the critical flow-delta $T$ measurement. This monitor would store hourly or daily data in battery-powered solid-state memory. The data would be processed when the unit was returned to the central processing facility. To guard against unnoticed degradation or catastrophic failure of the mechanical components, a trouble light detection unit would be installed in a place with high visibility to the owner or operator. Utility bill analysis could provide a reasonable estimate of the energy savings. The system could provide a lower cost method of examining climatic or occupant interactions on specific systems or components.

The three monitoring concepts just described would fill the gaps which are not filled by the NSDN concept alone. The present NSDN system is too expensive to provide a large data sample for climate or occupant interaction. Also, the data requirements for such data samples do not require the NSDN level of measurement. The NSDN did not collect appropriate data about the design and installation process or the actual and estimated costs of such projects to provide architects and engineers with data on the startup phases of a solar project. 


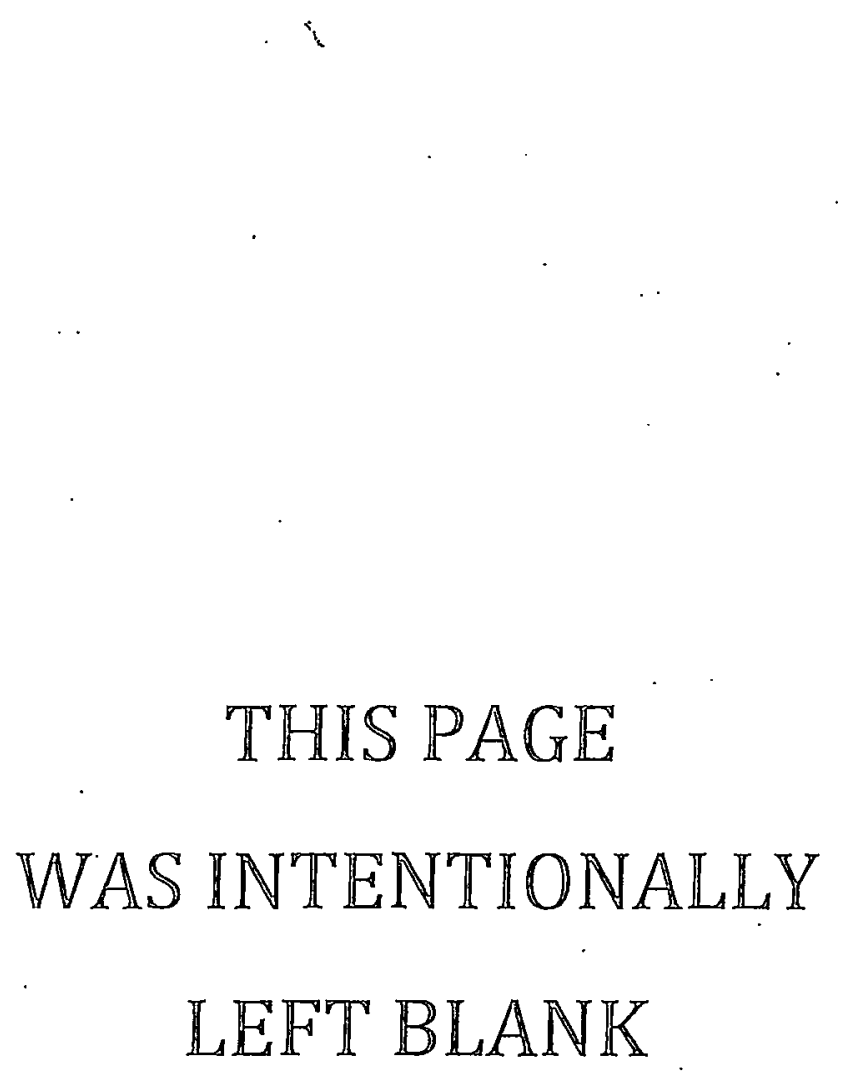


*1. Instrumentation Installation Guidelines, March 1981, Parts 1 , 2, and 3, SOLAR/0001-81/15, Vitro Laboratories, Silver Spring, Maryland.

2. Hy-Cal Engineering Data Sheet CF-391.6, "Comparison Chart of Various Temperature Sensors," Hy-Cal Engineering, Santa Fe Springs, California, 1980 .

*3. The National Solar Data Network, SOLAR/0003-80/17, Department of Energy, Vitro Laboratories, Silver Spring, Maryland, 1980 .

4. NSDN Data Accuracy Study, Technical Memo 03200.8, Part I, Technical Discussion, and Part 11 , Appendices, Vitro Laboratories, Silver Spring, Maryland, 1980. 
APPENDIX A

DATALOGGER MANUFACTURERS 
APPENDIX A

DATALOGGER MANUFACTURERS

MANUFACTURER

A.D. Data Systems, Inc.

ACUREX Corporation

Autodata Division

ADAC Corporation

Aeolian Kinetics

Analog Devices

Analogic Corporation

Barber-Colman Company

Industrial Instruments

Division

Campbell Scientific, Inc.

Crodata Corporation

Cybersystems, Inc.

Cyborg Corporation

Data Translation
ADDRESS

200 Commerce Drive

Rochester, NY 14623

555 Clyde Avenue

P.0. Box 7555

Mountain View, CA 94039

70 Tower Office Park

Woburn, MA 01801

P. O. Box 100

Providence, RI 02901

Route I, Industrial Park P.0. BoX 280

Norwood, MA 02062

14 Electronics Avenue

Danvers, MA 01923

1354 Clifford Avenue

P. O. Box 2940

Loves Park, IL 61132

815 W. $1800 \mathrm{~N}$.

P. O. Box 551

Logan, UT 84321

255 Bear Hill Road

Waltham, MA 02154

7540 S. Memorial Parkway Huntsville, AL 35802

SS Chapel street

Newton, MA 02158

100 Locke Drive

Marlboro, MA 01752
TELEPHONE NUMBER

(716) 334-9649

(415) 964-2941

(617) 935-6668

(401) 421-5033

(617) $329-4700$

(617) 777-4500

(815) 877-0241

(801) 753-2342

(617) 890-0145

(205) $883-4410$

(617) 964-9020

(617) $481-3700$ 
MANUFACTURER

Datasentry, Inc.

Digitee Corporation

Doric Scientific

Div. of Emerson

Electric Co.

Dranetz Fngineering

Laboratories, Inc.

Esterline Angus

Instrument Corp.

Fowlkes Engineering

John Fluke Mfg. Co.,

Inc.

Gould Inc.

Programmable Control

Division

Hewlett-Packard

I THACO, Inc.

CompuDAS Division

J EW Inatruments. Inc.

Kaye Inatruments, Ins.

Linseis Inc.

Metra Byte Corp.
ADDRESS

P.0. Box 1157

Minnetonka, MN 55343

918 Woodley Road

P. 0. Box 458

Dayton, $O H 45401$

3883 Ruffin Road

San Diego, CA 92123

1000 New Durham Road

Edison, NJ 08818

P.O. Box 24000

Indianapolis, IN 46224

31 Gardner Park Drive

Bozeman, MT 59715

P. 0. Box C9090

Everett, WA 98206

P. 0. Box 3083

Andover, MA 01810

4 ihoke Cherry Ruad

Rockville, MO 20850

735 W. Clinton Street

P.0. Box 6437

I thaca, NY 14851

4800 Mustang Circle

New. Brighton, MN 55112

15 De Angelo Drive

Bedford, MA 01730

P.0. Box 666

Princeton-Jct., NJ 08550

254 Tosca Drive

Stoughton, MA 02072
(800) 426-0361

(206) 356-5400

(609) 799-6282

TELEPHONE NUMBER

$(612) 933-9929$

(513) 254-6251

(714) $565-4415$

(201) 287-3680

(317) 2'17-9164

(406) 587-3779

(617) $475-4700$

(301) $258=2000$

(607) 272-7640

(612) 784-5708

(617) 275-0300

(617) 344-1990 
MANUFACTURER

Molytek, Inc.

Monitor Labs, Inc.

Novatech Corporation

Omega Engineering, Inc.

Omnidata International

Pacific Instruments

Piñon Systems $\varepsilon$

Technology

Preston Scientific Inc.

Syscon International

Yokogawa Corp. of America
2417 Smallman Street

Pittsburg, PA 15222

(412) 261-9030

10180 Scripps Ranch Blvd.

San Diego, CA. 92131

226 Commerce Street

P. 0. Box 324

Broomfield, CO 80020

One Omega Drlve

Box 4047

Stamford, CT 06907

750 W. $200 \mathrm{~N}$.

P. 0. Box 3489

Logan, UT 84321

2355 Whitman Road

Concord, CA 94518

(415) $827-9010$

2524 East Vine Drive

Ft. Collins, Co 80524

(303) $484-4653$

805 E. Cerritos Avenue Anaheim, CA 92805

(714) $776-6400$

$1108 \mathrm{~S}$. High Street South Bend, IN 46618

(219) 232-2900

Dart Road

Shenandoah, GA 30265

(404) 253-7000 
APPENDIX B

DATALOGGER SPECIFICATIONS 
Table B-1. DATALOGGER SPECIFICATIONS

\begin{tabular}{|c|c|c|c|c|}
\hline & & CTURER & & \\
\hline & & NUMBER & & \\
\hline $\begin{array}{c}\text { A.D. DATA } \\
\text { SYSTEMS, INC. } \\
\text { MX }\end{array}$ & $\begin{array}{l}\text { ACUREX } \\
\text { AUTOCALLC }\end{array}$ & $\begin{array}{l}\text { CAMPBELL } \\
\text { SCIENTIFIC } \\
\text { CRT }\end{array}$ & $\begin{array}{l}\text { CAMPBELL } \\
\text { SCIENTIFIC } \\
2 I X\end{array}$ & $\begin{array}{l}\text { CR OOATA } \\
\text { M } 1600 \mathrm{~L}\end{array}$ \\
\hline
\end{tabular}

\section{DAIA COLLECTION}

VOLTAGE RAMGE (OC)
AUTO RAMGING
ACCURACY
RESOLUTION
COMMOH MOOE REJECTION
NORMAL MODE REJECTIOB
TYPE TEMPERATURE SEMSORS
PULSE COUNTER/TIMER
NUMBER OF CHAHNELS
MAXIMUM SCAM RATE (POP SOCONA)
MULTIPLE SCAN RATES
MATHEMATIC OPERATIOHS
STORAGE

\begin{tabular}{|c|c|c|c|c|}
\hline $0 \pm 40 \mathrm{~V}$ & $0 \pm 10 \mathrm{~V}$ & $0 \pm 5 V$ & $0 \pm 5 V$ & $=1$ v (3) \\
\hline ros & Yos & No & No & No \\
\hline $20.1: F 5 Q$ & $0.3^{\circ} \mathrm{C}$ & $0.028 \mathrm{FS}$ & $0.18 \mathrm{FS}$ & $\pm 0.18 \mathrm{FS}$ \\
\hline 1500 & 14 bit & 16 bit & 14 bit & 12 bit \\
\hline $120 \mathrm{~dB}$ & $140 \mathrm{~dB}$ & $140 \mathrm{d \theta}$ & $140 \mathrm{~dB}$ & $\star$ \\
\hline$\pi$ & $70 \mathrm{~dB}$ & $70 \mathrm{~dB}$ & $70 \mathrm{~dB}$ & $n$ \\
\hline RTO, J,E,T,K & RTD, J,K, T, R, S, E, B & $R T D, J, E, T, K$ & RTD, J,E,T,K & RTD (4) \\
\hline 4 & Yes & Yes & Yes & Yes \\
\hline $50-1,000$ & 256 & 448 & $16(8)$ & 100 \\
\hline $\begin{array}{l}\text { Temp } 10 \\
\text { Analog } 100 .\end{array}$ & 20 & 250 & 250 & 50 \\
\hline * & Yes & ros & res & res \\
\hline$\star$ & Yes & Yes & res & No \\
\hline
\end{tabular}

TYPE OF STORAGE

STORAGE CAPACITY (data DOInEs)

$\begin{array}{ll}\text { RAM } & \text { RAM } \\ 1.000 & 50.000\end{array}$

RAM

30,000

Yes

32,000

Yes

Tape

POHER LOSS PROTECTIOA

Yes

$\begin{array}{ll}\text { Yes } & \text { YOS } \\ * & 19,200 \\ \text { HEEE/RS232 } & \text { No } \\ \text { * } & 2-R 5232 \\ & \text { ASC11 }\end{array}$

Yes

19.200

res

$2-R 5232$

Binary/ascil

Yes
19.200

Yes

$1-R 5232$

Binary/ASCII

66,000

Yes

DATA FORMAT

OPERATIOH AMO MAIUTEMANCE

POWER FAILURE RESTART
PROGRAM LOCKOUT
REMOTE PROGRAM OOWHLOAO
AWO SOFTWARE RESTART
OPERATING ENYIRONGEHTAL RANGE
TEHPERATURE
RE LATIVE HUH OITY
POWER REQUIREMENT
BATTERY BACKUP
CLOCK
PROGRAM
OATA COLLECTION
PRINTER OUTPUT PORT
REPAIR BY BOARD SWAP

$\begin{array}{ll}* & \begin{array}{l}\text { Yes } \\ \text { res }\end{array} \\ \text { Yes } \\ 0 \text { to } 70^{\circ} \mathrm{C} & 02060^{\circ} \mathrm{C} \\ 010908 & 010908 \\ 115 / 220 & 115 / 220 \\ \text { Yes } & \text { Yes } \\ \text { No } & \text { Nour } \\ \text { No } & \text { Yes } \\ \text { Yes } & \text { Yes } \\ \text { Yes } & \end{array}$

Yes
Yes
Yes
$-251050^{\circ} \mathrm{C}$
020908
$120 / 240$
Yes
Yes
Yes
Yes

Yes
res
res
$-251050^{\circ} \mathrm{C}$
010908
$120 / 240$
res
res
Yes
res
r

res

No IEEE/AS 232 ECMA/ANS I

(1) Values for analog $0.4000 \mathrm{~V} F S$, 5.000V FS, And $40.000 \pm 0.18$ FS \pm 1 count.

Tomperatures \pm 0 . 18 of reading \pm 1 digit.

(2) Each channel can be multiplexed to carry 30 temperature readings.

(a) Input interface cards used to precondition signals to the l-vole range.

(4) Also thermistors and thermocouples (specific iypes of thermocouples not specified).

* Denoies unavailahle Aata. 


\section{Table B-1. DATALOGGER SPECIFICATIONS (Continued)}

\begin{tabular}{|c|c|c|c|c|c|}
\hline & \multicolumn{5}{|c|}{$\begin{array}{l}\text { MANUFACTURER } \\
\text { MODEL NUMBER }\end{array}$} \\
\hline & $\begin{array}{l}\text { CYBORG } \\
\text { ISAAC } \\
2000\end{array}$ & $\begin{array}{l}\text { DORIC } \\
235\end{array}$ & $\begin{array}{l}\text { ESTERL INE } \\
\text { ANGUS } \\
\text { OATA SYSTEM } \\
\text { ARL 250 }\end{array}$ & $\begin{array}{l}\text { FLUKE } \\
2280 A\end{array}$ & $\begin{array}{l}\text { HEVLETT- } \\
\text { PACKARD } \\
30540 L\end{array}$ \\
\hline \multicolumn{6}{|l|}{ DATA COLLECTION } \\
\hline Voltage range (oC) & $0 \pm 10 \mathrm{~V}$ & $0 \pm 20 \mathrm{~V}$ & $0 \pm 60 \mathrm{~V}$ & $0 \pm 64 \mathrm{~V}$ & 0.100 \\
\hline AUTO RANGING & $\star$ & No & res & res & Yes \\
\hline ACCURACY & $+0.058 \mathrm{Fs}$ & $0.018 \mathrm{FC}$ & $0.258 \mathrm{FS}$ & $\pm 0.018 \mathrm{FC}$ & 0.0068 \\
\hline RESOLUTION & 12 bit & 16 bit & . & 16 bit & $\because$ \\
\hline CONMON MODE REJECTION & $70 \mathrm{~dB}$ & * & $110 \mathrm{d \theta}$ & $160 \mathrm{d \theta}$ & $104 \mathrm{~dB}$ \\
\hline MORMAL MODE REJECTION & $\Rightarrow$ & $80 \mathrm{~dB}$ & $50 \mathrm{~dB}$ & $60 \mathrm{~dB}$ & $60 \mathrm{~dB}$ \\
\hline ITPE TEMPERATURE SENSORS & ATD, J,K,T,ER, & RTO, J,R,R,S,T,E,B & RTU. J,R,E,T,R,S & ${ }_{S, N, B}^{R T O}, J, K, T, E, R_{1}$ & $R, 5, i^{R T O}, R, K$ \\
\hline PULSE COUNTER/TIMER & 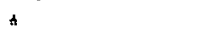 & $n$ & Yos & at & ins \\
\hline NUMBEA OF CHAMMELS & 1,000 & $100+96$ & yo & 1,300 & 1.000 \\
\hline MAXIMUN SCAN RATE (per second) & 200.000 & 14 & - & 20 & 116 \\
\hline MULTIPLE SCAM RATES & res & res & * & res & No \\
\hline MATHEMATIC OPERATIOHS & Yes & ves & ros & res & res \\
\hline \multicolumn{6}{|l|}{ STORAGE } \\
\hline TYPE OF STORAGE & RAM & None & RAM & Tape & Tape \\
\hline STORAGE CAPACTTY (data points) & 65,000 & None & 1 scan & 50,000 & 16,000 \\
\hline POVER LOSS PROTECTION & No & None & no & Yes & res \\
\hline \multicolumn{6}{|l|}{ COMAUNICATIONS } \\
\hline REMOTE CALL-UP & res & No & res & res & res (1) \\
\hline gAUO RATE (MAX) & 19,200 & 9,600 & 9.600 & 19,200 & 19,200 \\
\hline ERROR CHECK & Yes & No & No & No & $\operatorname{res}(\theta)$ \\
\hline TYPE OF INTERFACE & IEEE/RS232 & R5 232 & R5232 & IEEE/RS232 & IEEE/RS232 \\
\hline DATA FORMAT & Ascil & Ascil & Ascil & ASCII/EBCOIC & Binary/Ascil \\
\hline \multicolumn{6}{|l|}{ OPERATION ANO MAINTEMANCE } \\
\hline POWER FAILURE RESTART & * & res & Mo & ver & Pes \\
\hline PROGRAM LOCKOUYH & ies & ies & $\cdot$ & res & res \\
\hline $\begin{array}{l}\text { REMOTE PROGRAN DOWNLOAD } \\
\text { AHO JOFTWARE NGSTART }\end{array}$ & r.e. & no & res & res & res (2) \\
\hline OPERATING ENVIRONGENTAL RANGE & & & & & \\
\hline $\begin{array}{l}\text { TEMPERATURE } \\
\text { RELATIVE HUHIDITY }\end{array}$ & 10 to $40^{\circ} \mathrm{C}$ & $\begin{array}{l}01050^{\circ} \mathrm{C} \\
0 \\
0\end{array}$ & $\begin{array}{l}3210122^{\circ} \mathrm{F} \\
0 \text { to } 9038\end{array}$ & $\begin{array}{lll}0 & 1050^{\circ} \mathrm{C} \\
0 & 10 & 958\end{array}$ & $\begin{array}{l}0.2050^{\circ} \mathrm{C} \\
.85 \%\end{array}$ \\
\hline $\begin{array}{l}\text { RELATIVE HUHIDITY } \\
\text { POUER REQUIREMENT }\end{array}$ & $\begin{array}{l}010908 \\
110\end{array}$ & $\begin{array}{l}010908 \\
110 / 240\end{array}$ & $\begin{array}{l}0 \text { to } 9148 \\
110 / 240\end{array}$ & $\begin{array}{l}010958 \\
110 / 240\end{array}$ & 1100 \\
\hline \multicolumn{6}{|l|}{ BATTERY BACKUP } \\
\hline clock & No & Yes & No & res & res \\
\hline PROGRAN & ӥo & pés & Nu & Yas & No \\
\hline DATA COLLECTION & ผ̈o & Yés & Ho & H* & un \\
\hline PRINTER UUTPUT PORT & res & res & Yes & res & Yes \\
\hline REPAIR OY BOARD SUAP & res & res & res & res & res \\
\hline
\end{tabular}

(5) $\pm 1 \%$ for RTDS.

(2)

* Dellutis unovailenle nara. 
Table B-1. DATALOGGER SPECIFICATIONS (Continued)

\begin{tabular}{|c|c|c|c|c|c|}
\hline & \multicolumn{5}{|c|}{$\begin{array}{l}\text { MANUFACTURER } \\
\text { MODEL NUMBER }\end{array}$} \\
\hline & $\begin{array}{l}\text { HEWLETT- } \\
\text { PACKARO } \\
\text { 30560L }\end{array}$ & $\begin{array}{l}\text { ITHACO } \\
\text { COMPUDAS } 1 / 10\end{array}$ & $\begin{array}{l}\begin{array}{l}\text { ITHACO } \\
\text { COMPUDAS } 3\end{array} \\
\text { COMPA }\end{array}$ & $\begin{array}{l}\text { JEN } \\
\text { I NSTRUMENTS } \\
\text { DIgI SCan LOC }\end{array}$ & $\begin{array}{l}\text { MONITOR } \\
\text { CABS } \\
9350\end{array}$ \\
\hline \multicolumn{6}{|l|}{ DATA COLLECTION } \\
\hline voltage range (oC) & $0-30$ & $0 \pm 10 \mathrm{~V}$ & $0 \pm 10 \mathrm{v}$ & 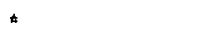 & $0-10$ \\
\hline AUTO RANGING & res & res & Yes & * & res \\
\hline ACCURACY & 0.028 & 0.0018 & 0.0018 & $0.05 i$ & 0.028 \\
\hline RESOLUTION & $18 \mathrm{bit}$ & $12 \mathrm{bit}$ & $16 \mathrm{bir}$ & 15 bis & 15 bit \\
\hline COMMON MODE REJECTION & $140 \mathrm{AB}$ & $100 \mathrm{~dB}$ & $126 \mathrm{AB}$ & $120 \mathrm{d \theta}$ & $120 \mathrm{d \theta}$ \\
\hline NORMAL RODE REJECTION & AO $d \theta$ & $51 d 8$ & $51 \triangle 8$ & * $\quad-2$ & $80 \mathrm{~dB}$ \\
\hline TYPE TEMPERATURE SENSORS & RTO, E,J,K,R,S,T & RTO, J.K.R,S.T.E & RTO, J,K,R,S,T,E & $\begin{array}{l}R T O, B, E, J, K, R \text {. } \\
S, T\end{array}$ & $\begin{array}{l}\text { RTO }, R, S, B, \\
E, J, K, T^{\prime}\end{array}$ \\
\hline PULSE COUNTER/TIMER & Yes & res & res & 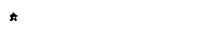 & No \\
\hline NUMBER OF CHANNELS & 60 & 120 & 420 & 128 & 1.120 \\
\hline MAXIMUM SCAN RATE (per second) & 28 & 3.300 & 5.000 & 80 & 1 \\
\hline MULTIPLE SCAM RATES & No & res & res & res & No \\
\hline MATHEMATIC OPERATIONS & Yes & res & Yes & no & res \\
\hline \multicolumn{6}{|l|}{ STORAGE } \\
\hline TYPE OF STORAGE & Tape & Tape/RAM & Tape/RAM & None & Tape \\
\hline STORAGE CAPACITY (dato points) & 16.000 & * & * & None & * \\
\hline POUER LOSS PROTECTION & res & Yes & Yes & res & res \\
\hline \multicolumn{6}{|l|}{ COMAUNICATIONS } \\
\hline REMOTE CALL-UP & res ${ }^{(0)}$ & res & res & No & res \\
\hline BaUd RATE (MAX) & 19.200 & 19.200 & 19.200 & 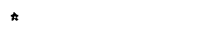 & 300 \\
\hline ERROA CHECK & res (1) & res $\infty$ & Yes (i) & No & No \\
\hline TYPE OF IMTERFACE & IEEE/RS232 & AS232 & 25232 & RS232 & RS232 \\
\hline DATA FORMAT & Binary/ascll & Binary/ascil & Binary/ascil & Ascil & Ascil \\
\hline \multicolumn{6}{|l|}{ OPERATION AMD MAIMTEMANCE } \\
\hline POUER FAILURE RESTART & res & Yes & Yes & res & res \\
\hline PROGRAM LOCKOUT & res & res & res & Yes & Yes \\
\hline $\begin{array}{l}\text { REMOTE PROGRAM OOWNLOAD } \\
\text { AND SOF TUARE RESTART }\end{array}$ & res $\theta$ & res & Yes & Yos & yes \\
\hline $\begin{array}{l}\text { OPERATING ENVIRONMENTAL RANGE } \\
\text { TEMPERATURE } \\
\text { RELATIVE HUMIDITY }\end{array}$ & $\begin{array}{l}010600^{\circ} \mathrm{C} \\
.858\end{array}$ & $\begin{array}{l}01060^{\circ} \mathrm{C} \\
<908\end{array}$ & $\begin{array}{l}0: 050^{\circ} \mathrm{C} \\
908^{\circ}\end{array}$ & $\begin{array}{lll}0 & 1050^{\circ} \mathrm{C} \\
0 & 1090 \%\end{array}$ & $\begin{array}{l}01050^{\circ} \mathrm{C} \\
.952\end{array}$ \\
\hline POWER REQUIREMENT & 118 & $110 / 240$ & $110 / 240$ & $110 / 240$ & $110 / 240$ \\
\hline \multicolumn{6}{|l|}{ BATTERY BACKUP } \\
\hline CLOCK & res & Yes & yes & res & res \\
\hline PROGRAM & No & res & Yes & res & res \\
\hline DATA FIDIIFETIOA & no & nu & No & no & No \\
\hline PRINTER OUTPUT PORT & res & Yes & res & res & res \\
\hline REPAIR OY BOARD SWAP & res & Yes & yos & . & Yes \\
\hline
\end{tabular}

